\title{
How can logistics service providers foster supply chain collaboration in logistics triads? Insights from the Italian grocery industry
}

\begin{abstract}
Purpose - Collaborative solutions are increasingly being proposed to generate value in supply chains. Concurrently, firms have progressively outsourced logistics operations to Logistics Service Providers (LSPs). However, many questions remain unsolved regarding the role played by LSPs in supporting supply chain collaboration (SCC) in triadic rather than dyadic contexts. The present study explores the relational mechanisms that LSPs can leverage to foster value creation through collaboration, elaborating on existing theory about SCC by focusing on logistics triads.

Design/methodology/approach - By leveraging the view of the Network Theory, a multiple case study approach was adopted. Seven cases having logistics triads as units of analysis were identified and analysed within the Italian grocery supply chain, allowing for empirical investigation with a middle-range approach in order to extend previous theory.

Findings - LSPs are pivotal actors that can actively promote SCC. LSPs can exploit large volumes and asset availability to increase efficiency while improving logistics flexibility, and develop regular and trustworthy relationships with the other triad members. Building upon their logistics capabilities and the relational mechanisms in place, LSPs can help manufacturers collaborate with retailers by improving mutual trust and communication, acting as trust builders or trust conductors within the triad.

Originality/value - The study explores the role of LSPs in logistics triads, extending the previous literature. It highlights that LSPs facilitate not only supply and demand integration but also relational integration between firms. Trust emerges as a fundamental building block for SCC, as LSPs can look beyond economic benefits to foster partnerships that empower the co-development of original collaborative solutions.
\end{abstract}




\section{Introduction}

A single company can seldom successfully compete in isolation (Ralston et al., 2017), and integrative and collaborative efforts are increasingly being recommended in supply chain management (Barratt, 2004; Soosay et al., 2008; Soosay and Hyland, 2015). Supply chain collaboration (SCC) has thus emerged as a major factor for the industry in developing and maintaining a competitive advantage and as an important research topic for the academic community (Singh et al., 2018). Driven by the increasing outsourcing of logistics operations to logistics service providers (LSPs), SCC has also gained rising importance in the logistics field (Gammelgaard et al., 2006; Sanchez Rodrigues et al., 2015).

Collaboration is strongly related to the relationships a firm has with other firms, which in turn influence behaviours and outcomes (Ellram and Cooper, 1990; Daugherty et al., 2006). This statement recalls the essence of Network Theory (NT), which "refers to the mechanisms and processes that interact with network structures to yield certain outcomes for individuals and groups" (Brass, 2002; Borgatti and Halgin, 2011). Consequently, this study adopted the NT as a theoretical lens (Håkansson and Snehota, 1995; Gulati et al., 2000), having as a central premise the belief that managing interorganisational relationships (seen as a set of ties that link the actors composing a network - Rowley, 1997; Borgatti and Halgin, 2011) is key to success (Zacharia et al., 2011; Andersson et al., 2019). From an NT perspective, outsourcing logistics operations to trusted third-party LSPs can be highly beneficial for firms (Ellram, 1990; Selviaridis and Spring, 2007). Furthermore, as the number of customers under the responsibility of the same LSP increases, opportunities to offer network interactions and synergies also increase (Zacharia et al., 2011).

In accordance with the view of NT, triads represent the fundamental building blocks of any network (Li and Choi, 2009). Triads also represent the minimum units of analysis needed to investigate collaboration adequately (Larson and Gammelgaard, 2001), as dyads cannot explain how the relationship between two players may affect a third actor or another relationship (Choi and $\mathrm{Wu}$, 2009; Borgatti and Li, 2009; Huang et al., 2020). However, previous studies in the managerial literature mainly explored dyadic setups (Siltaloppi and Vargo, 2017), and few contributions explored the figure of LSPs in logistics triads or investigated the collaborative efforts required to implement SCC solutions (Vlachos and Dyra, 2020). Moreover, the available literature has focused on LSPs as conductors of material and information flows, overlooking the relational enablers of SCC (Yu and Huo, 2018). Also, relational capital can be a critical resource to shape and maintain a competitive advantage (Vlachos and Dyra, 2020). Relational capital normally encompasses the trust, respect, and friendship that actors have developed with each other through a history of interactions (Yu and Huo, 2018). Today, trust-building is a vital competitive capability (Ralston et al., 2017), but the 
mechanisms behind relational capital creation and utilisation are not well-understood (Fawcett et al., 2017).

As further research has been recommended to better understand the role of LSPs in facilitating SCC and the relational mechanisms driving SCC through collaborative solutions where LSPs are key players (Sengupta et al., 2018; Vlachos and Dyra, 2020), the following research questions have been formulated:

1. How do LSPs facilitate SCC between manufacturers and retailers in logistics triads?

2. How do LSPs develop relational integration in logistics triads?

The present study thus aims to explore how LSPs can foster and promote value creation through collaboration, elaborating on existing theory about SCC by leveraging the perspective of NT within logistics triads (i.e. triads involving sellers, buyers, and LSPs). In this way, it builds upon NT to tackle the problem within a given empirical domain, resulting in a mid-range theory approach (Stank et al., 2017). A multiple case study approach has been adopted, and seven cases having logistics triads as units of analysis were identified and analysed. The Italian grocery supply chain was investigated due to its economic significance, as it is placed among the top five markets in Europe for logistics volumes and turnover generated, and it is one of the fastest-growing sectors across Europe (Nielsen, 2019). Moreover, it is characterised by the increasing importance acknowledged to LSPs in promoting competitiveness (Colicchia et al., 2017; Marchet et al., 2017).

On the one hand, this research explores SCC, shedding new light on the important and proactive role of LSPs in the adoption of collaborative solutions. LSPs can facilitate SCC between manufacturers and retailers, leveraging trust as a fundamental building block for SCC in triadic settings. On the other hand, it provides LSPs with insights useful to study value creation strategies through SCC. The research can also stimulate the industry to spread collaborative practices further while helping their customers consider network-related benefits when choosing logistics partners.

The remainder of the paper is organised as follows. The next section contains an analysis of the related literature, followed by a section about the research methodology. Findings are subsequently first described, and thereafter discussed. Finally, conclusions are drawn, together with the possible streams for future research. 


\section{Related literature}

\section{Logistics Service Providers (LSPs) and Supply Chain Collaboration (SCC)}

SCC has often been defined as two or more companies working together to build a competitive advantage, as higher profits can be achieved this way rather than by acting alone (Barratt, 2004; Simatupang and Sridharan, 2005; Soosay and Hyland, 2015). This definition recalls the Resourcebased theory (Barney, 1991), but the concept that firms hold resources giving them a competitive advantage has been further expanded from firm-level to highlight how resources can be synergistically combined or exploited by supply chain partners (Zacharia et al., 2011) that can represent the nodes or actors in a network along with the ties that link them (Borgatti and Halgin, 2011). Relational ties between actors are channels for transfer of "flow" of resources (Rowley, 1997), and SCC can help increase efficiency, improving the use of assets and reducing both inventories and trucks through consolidation, also improving service level to final customers thanks to a higher availability of products (Caputo and Minnino, 1996; Doukidis et al., 2007; Singh and Power, 2009).

As concerns logistics operations, firms have increasingly been outsourcing them to LSPs to focus on their core competencies while opting for the most efficient means of moving products (Bask, 2001; Bottani and Rizzi, 2006). LSPs have traditionally supplied basic services, such as warehousing or transport (Wilding and Juriado, 2004; Marchet et al., 2017), being considered as asset-based providers due to the ownership of physical assets, such as trucks or warehouses (Razzaque and Sheng, 1998). Nevertheless, in recent years the range of services offered by LSPs has increased, as they started to bundle core transport and warehousing activities with value-adding services to combat tight margins (Selviaridis and Norrman, 2015). To date, shippers and LSPs are moving towards more meaningful partnerships, with shippers relying on LSPs to provide SCC solutions and create a competitive advantage (Marchet et al., 2017). From an NT perspective, outsourcing logistics activities to trusted LSPs allows firms to manage their supply chains as single entities through the application of relationship building (Ellram, 1990; Andersson and Norrman, 2002; Zacharia et al., 2011).

As a result, a change in the LSP's role has occurred, making them important supporters of SCC (Bask, 2001; Gammelgaard et al., 2006). As LSPs are in the middle of other members of the supply chain, they can collaborate with many other entities in the network (Zacharia et al., 2011; Sanchez Rodrigues et al., 2015). They can help cope with several challenges, including delays caused by poor logistics and communication infrastructure, lack of coordination, or conflict of interest between customers and suppliers (Vlachos and Dyra, 2020). 


\section{LSPs and SCC within logistics triads}

Supply chain relationships have mainly been explored in a dyadic perspective (Soosay and Hyland, 2015). Nonetheless, dyads may not be appropriate to understand the complexity of modern supply chains completely, as they cannot capture the multidirectional and complex relationships that "constitute contexts for collaboration, competition, and value creation" (Siltaloppi and Vargo, 2017; p. 396). Therefore, the use of triadic models to capture the basic essence of networks in supply chains has been proposed (Borgatti and Li, 2009; Choi and Wu, 2009; Huang et al., 2020).

Triads are inter-organisational structures that require i) the association of three actors and ii) the connectedness of relations between the three actors (Vedel et al., 2016). Triads have also been proposed as the minimum unit of analysis for investigating collaboration in the logistics field (Beier, 1989) and logistics triads are specifically defined as "cooperative, three-way relationships between a buyer of goods, the supplier of those goods and an LSP moving and/or storing the goods between buyer and supplier" (Larson and Gammelgaard, 2001; p. 71). They offer win-win-win opportunities, as LSPs can improve collaboration between the actors of the triad by offering value-adding activities and innovative solutions towards higher supply chain value through better cost efficiency and effectiveness (Marchet et al., 2017; Vlachos and Dyra, 2020).

In a triad, each member can act as an intermediary between the other two, playing a dual task whether to ally or to separate (Choi and $\mathrm{Wu}, 2009$ ). In a setting with a seller/manufacturer, a buyer/retailer, and an LSP, internal or external coalitions may emerge where two parties form alliances to turn back the power and authority of the stronger party (Salo et al., 2009; Siltaloppi and Vargo, 2017). On the other hand, LSPs can behave as non-partisan mediators, generating harmony and balancing out sources of conflict between two disputing parties (Simmel, 1950). In this perspective, LSPs may be considered facilitators or conciliators in the value creation process (Nätti et al., 2014). Moreover, when LSPs hold responsibilities over strategic decision-making and directly control a portion of the supply network, they can play an active role in the integration and coordination of the supply chain, acting, for example, as neutral arbitrators (Simmel, 1950) or orchestrators (Dharanaj and Parkhe, 2006; Zacharia et al., 2011). For instance, when behaving as tertius iungens, an LSP can join two opposing actors in existing cooperative initiatives by being the guarantor of fair and correct behaviours and then propose new solutions around which the parties can collaborate (Obstfeld, 2005; Li and Choi, 2009).

Therefore, LSPs can actively support SCC in triads, collaborating with customers and customers' direct partners, even collaborating with every actor in the chain (Fabbe-Costes and Roussat, 2011). Indeed, LSPs are usually conceived of as neutral entities, able to suggest and foster collaborative solutions as third-party neutral actors with sufficient visibility along the supply chain (Zacharia et al., 
2011). LSPs may also increase their sphere and extent of chain integration, working both vertically with other members of the supply chain and horizontally with other LSPs (Fabbe-Costes et al., 2008; Fabbe-Costes and Roussat, 2011). Nevertheless, LSPs do not necessarily contribute to SCC, such as when they behave as oppressor or tertius gaudens to sow or support discord between the other triad members and gain a dominating position (Simmel, 1950; Li and Choi, 2009).

\section{The importance of LSPs in developing collaborative solutions}

LSPs can pursue different strategies to create value for their customers, but most of the collaborative solutions proposed in the literature concerned dyadic buyer-supplier relationships (Olorunniwo and Li, 2010; Soosay and Hyland, 2015). Those solutions included electronic data interchange (EDI), vendor managed inventory (VMI), continuous replenishment program (CRP), efficient consumer response (ECR), and collaborative planning, forecasting and replenishment (CPFR) (Holmström, 1998; Barratt and Oliveira, 2001; Holmström et al., 2002; Attaran and Attaran, 2007; Pramatari, 2007; Claassen et al., 2008).

For instance, Lai et al. (2008) emphasised that EDI solutions can help LSPs integrate with different business partners. They also allow for reducing costs, providing innovative and customised services, and improving service quality, thus conferring a service competitive advantage (Hill and Scudder, 2002). Indeed, many manufacturers still cannot make use of EDI due either to prohibitive cost in EDI implementation or to proprietary interfaces unique to individual retailers (Leonard and Clemons Davis, 2006). In addition, LSPs can offer warehousing services to multiple customers (usually manufacturers), holding their inventories in the same facility, thereby increasing operational efficiency through higher scale economies (Kopczak et al., 2000). Moreover, Fawcett et al. (2015) described drop-and-hook operations (i.e. loading a trailer while a driver is on the clock, thus minimising live-loading) as an important way for LSPs to improve operational efficiency and provide customers with flexibility and convenience. It allows for reducing operational time and increasing asset usage and has also been proposed in maritime logistics to manage containers at ports and at inland terminals (Zhen et al., 2013; Jin et al., 2016).

However, few studies have explored collaborative solutions explicitly considering the LSP as part of a logistics triad. Within triads, value creation by LSPs can be related not only to interactions with direct customers but also with the other member of the triad (Zacharia et al., 2011). For example, some scholars proposed VMI in a triadic structure, shifting the replenishment decisions from the supplier (manufacturer) to the LSP to reduce the supplier's logistics costs and increase its short-term profits (Yang and Liu, 2007; Daoping et al., 2011). VMI entails manufacturers/suppliers making the main inventory replenishment decisions for the consuming organisation, either a wholesaler or retailer 
(Waller et al., 1999; Barratt and Oliveira, 2001; Claassen et al., 2008). Based on the shared information received from the latter, manufacturers/suppliers can achieve benefits related to the reduction of lost sales and transport costs (Çetinkaya and Lee, 2000; Yao and Dresner, 2008). By shifting ownership and control of the goods from the vendor/supplier to the LSPs, logistics costs can be further reduced (Daoping et al., 2011).

\section{Trust-building and relational mechanisms in logistics triads}

Besides finding that the traditional focus of previous research on SCC is on dyadic relationships and highlighting the importance of shifting this focus onto triadic relationships, an important factor emerging from the extant literature is the need to address the relational mechanisms that occur in logistics triads (Vlachos and Dyra, 2020). LSPs have traditionally been seen as conductors of material and information flows, largely eschewing the relational enablers of collaborative solutions within dyads or triads in favour of their development and effectiveness (Selviaridis and Spring, 2007; Sengupta et al., 2018). However, LSPs can facilitate not only supply and demand integration, but also relational integration ( $\mathrm{Yu}$ and Huo, 2018). Consequently, the issue of trust-building in logistics triads is becoming increasingly relevant in the context of SCC (Vlachos and Dyra, 2020). It is widely acknowledged that collaborative solutions could bring significant economic benefits to suppliers and buyers, but at the same time significant levels of inter-organisational trust are required to avoid exploitative situations (Fawcett et al., 2017). Although trust-building is a vital competitive capability for SCC (Ralston et al., 2017), it is rare and difficult to gain (Barratt, 2004), as challenges could emerge because of lack of coordination or conflicts of interest between retailers and suppliers and, in general, among parties (Vlachos and Bourlakis, 2006).

However, in line with NT "the expansion of the alliance and growing density of ties" (Siltaloppi and Vargo, 2017; p. 404) can be emblematic of trust, and LSPs may serve as third-party enablers of trust-building processes fostering the adoption of SCC initiatives. In this sense, LSPs can intervene and coordinate triadic flows and relationships, building trust with both retailers and suppliers and, thus, be able to alter relationship quality (relational embeddedness) or create new relationships with new suppliers (structural embeddedness) (Li and Choi, 2009). Besides, LSPs can offer unique production-distribution solutions that can be a source of differentiation and competitive advantage over other triadic configurations (Vlachos and Dyra, 2020). Triad-specific investments can support formal and informal interactions based on trust that provide these unique solutions, and relational commitment capabilities emerge as key elements to transform relational capital (i.e. trust) into relational rents (Fawcett et al., 2017). 
Such capabilities can refer to relationship capital that supply chain actors create via valuecreating interactions, mutual trust, and processes specific to the chosen supply chain configuration (Yu and Huo, 2018). LSPs can actively build trust among the actors of a triad, proactively building integration processes that provide value to all the parties involved so that all parties can trust the triad more (Vlachos and Dyra, 2020). As triads evolve, actors can then explore and develop further collaborative solutions (Yu and Huo, 2018). Potentially, LSPs may dedicate assets and resources to specific partnerships or re-configure existing functions to serve a specific customer or support their suppliers (Fawcett et al., 2017). In this way, a triad becomes more integrated, which gives LSPs the opportunity "to act as triad integrators, as they are in a favourable position in terms of relational capital (they may know suppliers better than retailers do and retailers better than suppliers do) and network power (they can prioritise sourcing from specific suppliers and show tolerance over some suppliers)" (Vlachos and Dyra, 2020; p. 297).

\section{Methodology}

\section{Research design}

Taking the perspective of NT to draw the boundaries of the research and define the unit of analysis, this study aims at exploring the role played by LSPs and the implied relational mechanisms to foster SCC through different collaborative solutions currently adopted in logistics triads. Empirical research on logistics triads has been recommended to complement previous studies addressing logistics service provision (Vlachos and Dyra, 2020). Even though well-established theories about SCC offer a solid basis to build upon, a need for mid-range theorising has arisen in the logistics field (Stank et al., 2017). Therefore, the study leverages NT to elaborate on existing knowledge (Voss et al., 2002; Ketokivi and Choi, 2014) while tackling a specific empirical context.

NT was adopted as it is built upon the principle that "firms seek efficiency of an entire network through interactions with other firms" (Zacharia et al., 2011; p. 41), while the growing density of ties that occur in a network of organisations (in our case, the logistics triad) can be emblematic of trust and representative of the involved relational mechanisms (Siltaloppi and Vargo, 2017). Such principles can constitute adequate theoretical support to frame this research, viewing the outsourcing of logistics operations to LSPs as a way to maximise the ability of firms to leverage relationships and relational mechanisms (Ellram and Cooper, 1990). Moreover, as LSPs become responsible for a larger number of supply chain members, their ability to offer more significant network interactions increases (Zacharia et al., 2011). NT also revolves around the concept of the network as a key pillar, and this makes it possible to overcome the traditional view of the dyad as unit of analysis, moving towards the triad seen as the building block of any network (Li and Choi, 2009). 
Formulating mid-range theories does not rely exclusively upon academic contributions, as knowledge may also stem from inductive, qualitative observations of practice (Stank et al., 2017). Therefore, qualitative case study research was conducted, as it facilitates comprehensiveness and understanding about how notional arguments are actually inflected in the empirical world (Eisenhardt, 1989). Consistent with the adopted theoretical lens of NT and with the aim of the research, logistics triads were selected as units of analysis. A multiple-case research design was then shaped to increase external validity and to reduce the risk of misjudging single events (Ellram, 1996; Voss et al., 2002). Multiple cases represent reproductions that can allow for the conceptualisation of a solid theoretical framework through analytical generalisation (Yin, 2009).

The grocery supply chain was selected as the object of the empirical stage of this research. On the one hand, the grocery industry constitutes a large part of consumers' budgets in all countries (Bourlakis and Weightman, 2004; Colicchia et al., 2017). On the other hand, the distribution of retail grocery products is often fragmented and inefficient, and collaborative solutions can be highly beneficial to improving distribution management practices (Hingley et al., 2011; Sanchez Rodrigues et al., 2015). Specifically, this research tackled the Italian grocery supply chain, which is one of the top five markets in Europe for logistics flows and turnover generated; it is also the fastest-growing market in terms of volumes and nominal value across Europe (Nielsen, 2019). Moreover, it is characterised by a higher level of fragmentation than that of other European countries (Colicchia et al., 2017), and the importance of LSPs in promoting the competitiveness of supply chains has been increasingly acknowledged (Marchet et al., 2017).

A purposive sampling strategy was adopted to identify the participating companies (Saunders et al., 2009), in line with recent contributions with a similar purpose (e.g. Sanchez Rodrigues et al., 2015). The approach of heterogeneous sampling suggested by Saunders et al. (2009) was applied, targeting 41 companies, including manufacturers, retailers, and LSPs. These companies were approached through contacts activated by two Italian universities, in collaboration with GS1 Italy, which is the main trade association of peers in the grocery industry in Italy and which provided the list of their company members. In order to be able to explore collaborative solutions, as well as to be sure to adequately investigate the role played by LSPs and the involved relational mechanisms within SCC through a set of comparable cases, the following sampling criteria were adopted within the Italian grocery sector:

- logistics triads were built by selecting large manufacturers, LSPs, and retailers, as they are recognised as being more prone to supporting collaboration along the chain. Moreover, because of their size, they are inclined to have more structured processes for establishing and 
maintaining relationships with buyers and sellers, including relational and trust-building mechanisms;

- manufacturers, LSPs and retailers operating in the dry food cluster of the grocery sector were selected since this cluster represents the largest one within the grocery industry in terms of exchanged logistics flows. Consequently, it constitutes a representative area to perform an exploratory study.

- each logistics triad was built selecting a different manufacturer, LSP, and retailer to ensure a high degree of variety in the array of analysed SCC solutions.

These criteria provided the researchers with a homogeneous, consistent and varied sample of comparable cases that suited the exploratory nature of this research. Seven cases (composed of logistics triads, involving 21 different companies) were considered; the choice was driven by the availability of the companies and the inclusion of representative or typical cases according to the sampling criteria described above (Yin, 2009). As suggested by Eisenhardt (1989), the sampling approach adopted in this study was based on the theoretical contribution offered by each case, delineating LSPs involvement in the Italian grocery supply chain according to the specific types of solutions proposed and looking for highly successful collaborative triads acting as empirical manifestations of such solutions.

The selected cases fit well inside the boundaries defined by the research purpose (Miles and Huberman, 1994). Two cases were deemed to represent logistics triads, despite involving multiple manufacturers or retailers; given the homogeneity of purpose of the companies involved, which acted jointly, they encompassed a single actor with reference to the research objective (in accordance with Hingley et al., 2011). Table 1 provides an overview of the features of the cases.

$$
\text { -Insert_Table_1- }
$$

Finally, the research team developed a research protocol that included key research issues, the proposed methodology and the interview guide (Yin, 2009). The interview guide was developed jointly by three of the researchers, including two full professors, and was shaped differently for suppliers (i.e. manufacturers), buyers (i.e. retailers) and LSPs. The different interview guides are reported in the Appendix. Figure 1 summarises the research process, developed following general guidelines proposed by Yin (2009). 


\section{Data collection}

Data collection was based on the research protocol, whose core was represented by different interview guides for each of the players involved. Interviews were conducted for each case, as they represent essential sources of case study information, allowing for the reconstruction of events and providing perceived causal inferences (Yin, 2009). To mitigate observer bias, multiple investigators were involved (Voss et al., 2002). Interviews involved different types of managers belonging to the logistics or the sales business functions, thus providing viewpoints from different functional domains within the firm. Most of the interviewees from the logistics side were also responsible for customer service management. Interview guides were shared in advance to allow interviewees to prepare data and documentation adequately. Due to the sensitive nature of the topic, confidentiality was guaranteed to interviewees. Therefore, neither companies' nor individuals' names will be revealed.

The widely adopted and accepted format of the funnel model was used for conducting semistructured interviews, starting with broad and open-ended questions, and then more specific questions as the interview proceeded (Voss et al., 2002). Despite focusing on key questions, interviewers also asked additional questions triggered by the answers of the respondents. By writing up memos with pattern codes after each interview, it was also possible to "look for recurring phrases or common threads in informants' accounts" (Miles and Huberman, 1994, p. 70).

Each interview lasted approximately 120 minutes, and instruments (recorder and written notes) were used to consolidate the collected information. Respondents from all companies in the triads were asked to describe the collaborative solutions they had been implementing, also focusing on the type of relationships developed and the related roles and actions undertaken. Multiple data sources were triangulated, not only during the interview but also by cross-checking information coming from the interviews of other participants mentioning similar practices. Information was also supported by other types of instruments, such as internal documents or industry reports (Ellram, 1996). An integrated case study database was developed, including interview transcriptions and codes, which were regularly updated during the research.

In total, 41 interviews were conducted in the period between September 2018 and May 2019. Once the data were collected, the draft of notes and the final documentation of each case were sent back to the interviewees for final approval, in order for them to check the level of validity and accuracy between the data collected and their ideas, thus increasing the study's reliability (Yin, 2009).

\section{Data analysis}

To pursue theory elaboration, a structured iteration between general theory and empirical data is required (Ketokivi and Choi, 2014). Therefore, the first step in the analysis was to code the collected 
data, as it is central to effective case research (Voss et al., 2002). A provisional initial list of coding categories was created from the literature (Yin, 2009). Examples of coding categories included the type of collaborative solutions, the behaviour of LSPs in designing and developing the SCC solutions, in introducing and spreading trust-building mechanisms, and the role and actions they took (Wallenburg, 2009; Zacharia et al., 2011; Fawcett et al., 2017). Categories were updated after each interview, continuously comparing the information collected from the different cases and reformulating it whenever more meaningful insights emerged (Voss et al., 2002; Yin, 2009). Both within-case and cross-case analyses were performed in order to identify important similarities and differences and capture specific factors (Eisenhardt, 1989).

Through open coding, empirical data were first broken down, examined, and compared to strengthen existing constructs and develop new categories (Ellram, 1996; Voss et al., 2002). Open coding paved the way for axial coding, to make connections between categories and look at their interactions (Yin, 2009). Initial codes were refined according to the themes that emerged from the data and grouped into higher-level categories (Ellram, 1996). For example, the roles that LSPs could play within logistics triads were examined and compared to constructs (e.g. tertius iungens) formerly proposed in the academic literature, also acknowledging how they contributed to trust-building. Lastly, findings from single cases were compared in a cross-case analysis for matching patterns (Eisenhardt, 1989; Yin, 2009).

\section{Research quality and trustworthiness}

Following Yin's approach (2009) to increase the quality and trustworthiness of the research, the dimensions of external validity, internal validity, construct validity and reliability were tackled as summarised in Table 2. The combination of multiple data sources through triangulation was used to corroborate evidence and to support construct validity, as well as to overcome the potential informant bias related to interviewing human subjects (e.g. including both logistics managers but also customer service and sales managers) (Eisenhardt, 1989). Internal and construct validity were supported by using variables derived from the literature and then triangulating data collected through interviews or secondary sources (Voss et al., 2002). Furthermore, searching for patterns through cross-case analyses increased the external validity of the results, while explanation building based on patterns and casual links also strengthened the study's internal validity (Ellram, 1996).

-Insert_Table_2- 
Findings: collaborative solutions promoted by LSPs within logistics triads (within case analysis)

\section{Case A: Drop-and-hook}

In case $\mathrm{A}$, the retailer offered shippers a platform to book delivery slots to unload goods at its distribution centre (DC). However, the retailer had strict receiving schedules that could affect inventory availability at the distribution centre if manufacturers' shipments arrived past that time window. As stated by the sales director of $\mathrm{LSP}_{\mathrm{A}}$, "Up to now, we could deliver only in the morning because after 11 A.M. deliveries were often rejected by retailers." Consequently, the costs associated with inefficiencies arising from retailer-imposed receiving restrictions were experienced by the LSP, and partially passed on to the manufacturer.

Although its actual customer is the manufacturer, the LSP leveraged its relationship with the retailer (i.e. its customer's customer) to offer a collaborative solution to improve unloading operations. The LSP booked a delivery slot as usual, then, rather than having to wait outside for permission to enter the DC, its trucks were immediately cleared for approaching docks. The full semitrailer was then dropped off from the truck and left at the DC yard, while the truck driver could hook up an empty semi-trailer to start a new delivery. The full semi-trailer that had been left at the DC was later unloaded by the retailer, according to its schedule. A notification about successful unloading was then sent to the LSP, who in turn informed the manufacturer.

This solution was built upon the LSP-retailer link, without a direct tie between the manufacturer and the retailer. Nevertheless, the whole triad benefitted from the solution, including the manufacturer. The LSP was able to achieve higher efficiency, thus being able to offer lower fees to the manufacturer. Thanks to this solution, the retailer improved unloading operations, reducing queues at unloading bays and smoothing trucks' arrivals. Also, it was possible to redistribute the loading/unloading workload over a longer time span, avoiding the usual concentration of unloading activities in the morning. Having semi-trailers be unloaded without any dependency on external suppliers, the retailer was also able to perform unloading operations in time slots that were not normally assigned to this activity. In addition to cost savings, this solution also allowed for improving drivers' working time and availability, which is a key problem nowadays, given the well-known shortage of truck drivers across Europe and the USA. As claimed by the logistics director of $\operatorname{LSP}_{\mathrm{A}}$, "Lack of drivers is the biggest problem we face today, and a vehicle moving for one hour is worth much more than the waiting fee paid by customers in case of prolonged waiting at DCs."

To make this solution feasible, large volumes were required in order to deliver full-truckloads, as the order size had to be large enough to (almost) fully load a semi-trailer that was shipped to the specific retailer, who in turn was required to accept the full semi-trailer and return an empty one. 
Moreover, the LSP held transport assets (i.e. trucks and semi-trailers) that were shared with the two other players: in this way, asset utilisation was increased, while the other players were provided with the flexibility of warehouse and transport operations that they might never be able to achieve by acting separately.

However, more importantly, strong partnerships had to be developed and a high level of trust had to be achieved among all triad members. Inventory ownership shifted from the manufacturer to the retailer when the full semi-trailer was dropped off from the truck and left at the DC yard; without a collaborative LSP, this solution would never have been possible. On the one hand, the LSP had established a long-term partnership with the manufacturer, being trustworthy enough to hold and manage inventories while the ownership remained with the manufacturer. Thanks to this partnership with its LSP (and the proposed solution), the manufacturer increased the availability of its products at the retailer's premises. On the other hand, the LSP had an established and trusted relationship with the retailer, to whom it offered high-quality logistics capabilities that allowed the goods to be accepted by the retailer without the standard control procedures, thus ensuring continuity of operations across a wider time window. In this way, the presence of an LSP "trusted" by both parties separately compensated for the absence of a direct link of trust between the manufacturer and the retailer, pushing towards the achievement of trust in the complete triad.

\section{Case B: Order pooling}

In case $\mathrm{B}$, the LSP used to carry out logistics operations on behalf of the manufacturer, facing some difficulties in optimising transport in case there were small order sizes towards a given retailer. Recognizing opportunities for increased efficiency through load consolidation when serving a given retailer, the LSP requested permission from the manufacturer (its customer) to autonomously discuss with the retailer (i.e. its customer's customer) changes in delivery dates, provided that the only change requested is the delivery date and not frequency or re-order policy. Thanks to its visibility over all destination points and delivery quantities, the LSP increased the use of the vehicles for each shipment as much as possible to achieve the best possible transport conditions.

As a result of increased efficiency, the LSP offered a discount to the retailer and lower fees to the manufacturer to activate the solution. Although monetary savings as a result of enhanced transport efficiency were significant, the solution nonetheless presented operational risks to both the manufacturer and its retail customers. In fact, the LSP's emphasis on load consolidation and transport savings could result in products arriving either too early or too late to meet consumer demand (i.e. inventory risks). In other words, both the manufacturer and its retail customer had to be reliant on the LSP to maintain optimal operational outcomes, even as it sought transport savings. 
While the LSP offered to share cost savings with both sides, interview participants indicated that, ultimately, what convinced all parties involved to agree on granting the LSP autonomy in load consolidation was the overall level of trust they had in the LSP, as well as the LSP's continued trust signaling. For instance, the LSP had served as a long-time partner of the manufacturer. During that time, the manufacturer had gradually entrusted its entire logistics operation to the LSP. The ability for the LSP to perform to promise was further matched by its investment in the relationship through dedicating specific logistics assets to serve the manufacturer. Additionally, significant information sharing, as evinced by the LSP's total visibility regarding the manufacturer-to-retailers network flows, also signaled the relational commitment espoused by all parties. Lastly, the LSP not only proactively promoted the solution by transparently sharing the purported benefits and risks with all parties but also provided the retailer with the option to confirm or refuse every consolidation proposal based on their operational impact. This entailed the LSP managing the replenishment flows from manufacturers to retailers in quite an autonomous and seamless way, which implied a certain level of knowledge of the operating mechanisms and an integration of processes and information across the supply chain among the players of the triad. Further opportunities for the solution were then identified, which would involve different retailers with nearby warehouses to exploit scale economies in transport. As acknowledged by the business development manager of LSPB, "If nearby retailers agreed on a given day to replenish their DCs, we might be able to fulfil all the orders with a single trip, improving truck use and routing schedules."

\section{Case C (Co-location)}

Within the context of a logistics triad, the inventories of manufacturers and retailers are usually located in two different logistics sites, and this creates several challenges due to potential redundancy of storage space, material handling equipment, other inventory management and transfer processes that can undermine an optimal inventory management process.

In case $\mathrm{C}$, to overcome these challenges, the LSP devised a solution according to which a logistics facility was created to hold inventories for both players in the same facility, keeping them separated and moving them across the warehouse once orders placed by the retailer had to be fulfilled. This inventory-pooling/co-location solution led to efficiency (and environmental) benefits since it removed the need to transport inventory across different facilities, reducing also the order-to-delivery lead time. As stated by the managing director of $\mathrm{LSP}_{\mathrm{C}}$, "the manufacturer and the retailer can share storage space within the same facility, thus reducing replenishment lead times. This allows for identifying and smoothing out inefficiencies driven by biased order policies." 
Thanks to its own logistics capabilities, the LSP put itself forward as a coordinator to optimise both physical and information flows related to warehouse and transport activities, signalling strong commitment and dedication of resources to this aim. Improved economies of scale and better operational efficiency could be obtained, but these were hardly attainable without the contribution of the LSP in the relationship of the triad. To achieve those benefits, it was essential for the manufacturer and the retailer to share mutual information on inventory, which is something that usually puts the counterparts in an uncomfortable spot.

To overcome this barrier and progressively increase the type and the timeliness of such information, the LSP had to join the two opposing actors by being the guarantor of fair and correct behaviour. Through the management of relational mechanisms and showing adequate logistics/information management capabilities, the LSP built trust in the links between manufacturer and retailer and assumed a coordinating role. It improved the communication flow between the two of them, acting as a guarantor and thereby improving mutual trust and optimising the relational mechanisms within the triad. This ultimately led to enhancing mutuality and transparency among the three actors.

Despite a few other examples that exist at an international level in the retail sector (e.g. Amazon Fulfilment services co-mingle marketplace sellers' inventory with company-owned inventory for fulfilling customer orders), this solution represents a novel approach to structuring logistics activities that has seen almost no application in the grocery supply chain and in the Italian context. Indeed, the LSP was no longer focused on a type of customer (either a manufacturer or retailer) but on the type of supply chain (i.e. the grocery one).

\section{Case D (DesAdv)}

In the context of grocery supply chains, communication and confirmation about the physical receipt of goods are essential to detect differences and discrepancies in products, quantities, or delivery dates. This usually happens through EDI messages called dispatch advice (DesAdv), sent by LSPs to manufacturers who in turn send them to retailers. EDI systems can streamline both operational and administrative processes within and across firm boundaries, as exemplified by many successful applications also in the grocery industry (e.g. Ciborra, 1995; Holmström, 1998).

However, significant challenges exist as some manufacturers are still not equipped with EDI due to its high implementation costs and because different retailers often require specific one-to-one IT interfaces. In 2018, only 6\% of European enterprises regularly used EDI (Eurostat, 2020), and as stated by the purchasing manager of $\mathrm{R}_{\mathrm{D}}$ "not all manufacturers can sustain DesAdv investment dedicated to a single retailer. They will do that only if they are able to use the tool with multiple 
retailers." Moreover, investing in relationship-specific assets may not be appropriate for any dyad, as this might create undesired dependencies that could expose either side to potential acts of opportunism (Barratt, 2004).

To overcome these barriers and improve the communication processes along the supply chain, the LSP put itself forward proposing to manufacturers the possibility to rely on its IT capabilities to communicate with retailers, developing a platform to generate an interface with multiple retailers on behalf of multiple manufacturers. This approach helped the manufacturers gain trust in the commitment and capabilities of the LSP and bolstered the trust-building process in the triad, since manufacturers accepted to mandate the LSP to take care of connecting them with the retailer. The benefits related to possessing early knowledge of the list of the incoming shipments and products were evident for the triad, resulting in a simplified data-entry process and goods consistency check at the time of unloading. In turn, this allowed for speeding up goods reception at DCs by reducing the unloading time (and therefore increasing truck travelling hours with higher utilisation rates for the LSP).

However, trust that information sharing through the platform of the LSP could happen reliably had to be built. Showing strong IT capabilities and the capacity to extend the existing EDI technological infrastructure were drivers for the LSP to extend trust along the triad. Such capabilities reinforced both the manufacturer's and retailer's view that the LSP played an essential role as an enabler of better communication, transparency and information exchange processes that can foster the efficiency of operations when the infrastructure is not available at all ends of the triad/supply chain.

\section{Case E (Pallet pooling)}

Wooden pallets are the most common handling unit in the grocery industry, yet pallet management is a very critical aspect. On the one hand, due to increasing automation levels within DCs, retailers require high-quality pallets and "reject unit loads because there are imperfections in the shape of the pallets and because they are made of low-quality wood", as claimed by the customer service manager of ME. On the other hand, the collaborative processes developed so far (e.g. issuing of a "pallet voucher" in the case of deferred pallet interchange) made both retailers and manufacturers unhappy. Manufacturers and retailers often disagreed about what the correct usage of pallet vouchers could be, and many disputes arose because of the lack of trust they mutually demonstrated to each other party when issuing or receiving vouchers. Consequently, pallet collection and re-distribution were inefficient, time-consuming, and not standardised. As acknowledged by $\mathrm{M}_{\mathrm{E}}$ logistics manager, 
"pallet management is a problem whose complexity increases day by day, both financially and administratively".

Recognizing this problematic issue of pallet management in the triad, the LSP offered to take control of the process: for payment of a fee for each shipped pallet, the LSP moved and repaired pallets and also managed the administration processes related to these items on behalf of its customers. The LSP thus introduced a new solution offering a "pallet pooling" service based on the standard EPAL pallet, leveraging the existing pallets re-collection activity at its customer's premises to show know-how, capabilities, and dedication to the solution of this conflictual relationship signalling commitment and building trust in the customers.

The manufacturer and the retailer gave the mandate to the LSP to take care of their pallet pools because the LSP was recognised as a neutral third party capable of safeguarding the interests of the different parties. As stated by the logistics manager of $\mathrm{ME}_{\mathrm{E}}$, "Thanks to pallet pooling, the whole chain experienced a dramatic reduction in the number of disputes between manufacturers and retailers." By improving mutual visibility of this critical shared asset within the triad and promoting collaborative practices, along with clearly demonstrating its capabilities and commitment, the LSP built and increased trust with and between the other two players. They also experienced a significant reduction in the complexity of the management of such a critical packaging asset - one which must be available when needed in the appropriate quantity and quality levels to avoid stops to both the production and distribution of goods. In turn, the LSP could optimise pallet re-collection, having visibility on where both the manufacturer and the retailer needed them.

\section{Case F (LSP's VMI)}

In Case F, the manufacturer and the retailer had already set up a VMI agreement and the LSP used to carry out the inventory management activity on behalf of the manufacturer. However, VMI agreements typically require a considerable effort put in by manufacturers and retailers in terms of time and resources devoted to the management of the VMI process. This is especially felt by manufacturers (as confirmed also by the interviewees who took part in this study), and also represents a challenge to the diffusion of VMI practices in the grocery industry. Not all manufacturers have sufficient capabilities and resources to take this task on, and retailers cannot completely compensate for the required effort.

To address this challenge, the LSP leveraged the already existing inventory management activity carried out on behalf of the manufacturer and proposed fully managing the replenishment process for the retailer on behalf of the manufacturer. However, initial reluctance was shown by the retailer since it meant having limited control of such a key process as inventories replenishment and leaving it in 
the hands of an external third party. As acknowledged by the SC manager of $\mathrm{R}_{\mathrm{F}}$, "to start a VMI collaboration, every partner must be ready. Giving away the keys to inventories, goals sharing and strong partnerships are required."

To overcome this obstacle, trust throughout the triad first needed to be built. A trust-signalling element was the proposal by the LSP to offer the manufacturer discounts on rates for logistics activities, with the latter in turn sharing these benefits with the retailer. All these elements showed a commitment to improve managerial practices and to avoid any opportunistic behaviour thanks to a transparent benefit-sharing mechanism. Moreover, the LSP openly shared information about its processes, increasing transparency about the details of the agreement, improving the management of the relational mechanisms and the extension of trust along the triad. This increased the mutual trust with the retailer, who started sharing information about past sales and future forecasts with higher frequency and timeliness. Besides the reduction of the LSP's rates, supply and demand uncertainty was reduced through improved communication, not only generating savings for all three actors but also improving the forecast accuracy for both the manufacturer and the retailer. As an additional benefit, the LSP could then organise its activities to improve its operational efficiency related to vehicle utilisation and saturation, while respecting the requirements from the retailer's side without the daily involvement of the manufacturer - who was freed from this duty.

Although this solution started from a dyadic agreement between the LSP and the manufacturer, the LSP successfully triggered a virtuous circle by extending trust. This circle was reinforced because the LSP, thanks to its commitment, information sharing capabilities and trust-signalling approach, was seen by the other players of the triad as a trusted enabler of better transparency and visibility of information across the chain of supply.

\section{Case G (Multi-retailer warehouse)}

The original context of case $G$ was characterised by four retailers which had their inventories scattered over four separate warehouses, each of them managed by the same LSP. This situation led to having redundancy of facilities and equipment, with consequent implications in terms of costs and resources involved that could not be shared across the retailers.

Thanks to the very large (joint) volumes of the four retailers, it was possible to develop a collaborative solution between the LSP and the four retailers to overcome the above-mentioned redundancy challenges. The four retailers agreed with the LSP about developing a single DC dedicated to the four of them, thus centralising their inventories within a multi-retailer warehouse. This centralisation process involved the aggregation of flows belonging to different retailers (while in multi-customer warehouses LSPs usually aggregate manufacturers' flows), and this was seen as a 
critical element by the four retailers who initially were reluctant to share single storage space with their competitors. The LSP had to step forward as guarantor of equal treatment and impartial allocation of resources to the four customers, which needed to be formalised in contractual agreements that required years to be defined. In addition, to show its commitment and capabilities the LSP also had to sustain a significant investment. As explained by the logistics director of $\operatorname{LSP}_{\mathrm{G}}$, "Together, the four retailers guaranteed volumes so significant so as to justify a completely new logistics facility, in an area bigger than $350,000 \mathrm{~m}^{2}$, including $150,000 \mathrm{~m}^{2}$ of floor area. A significant investment in automation was justified, as well, with an automated warehouse to stock full pallets with more than 33,000 pallet locations and a mini-load system for the management of 4,000 different SKUs. $"$

By showing such commitment, contractual expertise and logistics capabilities, and by leveraging the strong long-term partnership in place with the retailers, the LSP built a sufficient level of trust to persuade the four customers to accept its proposal. The trust mechanisms developed in the previous years, thus, represented a solid base upon which to build future plans. The LSP acted as the key orchestrator, improving material and information flow management but also fostering relational integration among different customers. In terms of benefits, economies of scale increased for both the retailers and the LSP, and manufacturers also achieved significant benefits. They were able to ship full-truck-loads to the new DC, thus achieving the most cost-effective transport conditions. Therefore, thanks to the LSP, the relationship between manufacturers and retailers improved with mutual gains.

\section{Cross-case analysis}

Some common themes emerged through the concurrent examination of the results of the study's empirical stage. These themes are common to the various cases analysed and span the range of the investigated triads, making it possible to perform a cross-case analysis.

\section{Collaborative solutions proposed by LSPs in logistics triads}

The case studies upheld concepts and notions previously formalised in the literature, but also presented new facets about already debated solutions within dyadic settings and provided an exploration of new solutions in triadic ones, thus enriching existing theory with original elements. Table 3 summarises and compares the findings within the case analysis and constitutes the backbone of the cross-case analysis through the proposed dimensions that embrace the main traits of the collaborative solutions. 
For example, in case F, a well-established practice such as VMI was explored. Although this is usually seen as part of the manufacturer-retailer relationship (Çetinkaya and Lee, 2000; Attaran and Attaran, 2007), it has also been proposed in a triadic structure to include LSPs (Yang and Liu, 2007; Daoping et al., 2011). Case F confirmed that LSPs could achieve higher efficiency than manufacturers alone, and showed how long-term benefits could overcome short-term ones, thanks to the savings LSPs can pursue by increasing their vehicle utilisation. Elaborating on the previous literature (e.g. Sanchez Rodrigues et al., 2015), case F also showed how LSPs can further increase the benefits of the solution through information sharing, which can improve trust and communication and support the introduction of transparent mechanisms for benefit sharing.

Case A exhibited a yard management application within grocery supply chains, while former contributions mainly pertained to maritime logistics (e.g. Jin et al., 2016). Drop-and-hook solutions can represent a common way for LSPs to improve operational efficiency (Fawcett et al., 2015) while providing customers with flexibility and convenience. However, case A offered a view on this solution by considering the whole logistics triad, and not only single LSPs. LSPs can act as fundamental enablers of drop-and-hook solutions, holding those assets to be shared with the other actors to improve costs and increase logistics flexibility. Moreover, case A showed how the solution implemented by the LSP benefitted not only the LSP itself, but also the manufacturer and the retailer composing the triad. It also showed that in order to put this solution into place a high level of trust had to be shared among all triad members, and that LSPs can foster and guarantee the trust level by offering their widely acknowledged logistics capabilities. In fact, the LSP had shown itself to be trustworthy enough so that the manufacturer let it manage its inventory on consignment, while the retailer trusted the LSP enough to allow it to bypass standard control procedures. Consequently, the LSP leveraged its dyadic trust with the two separate players, both of which were lacking direct trust between themselves, to effectively serve as a conduit of trust towards building a successful triadic collaborative solution.

Case D confirmed that solutions built upon EDI could help streamline the supply chain and integrate different business partners, emphasising the important role played by LSPs in this process (Lai et al., 2008). Case D showed that their role is crucial because many manufacturers still remain without EDI capabilities, and LSPs can serve as vital collaborators by taking the responsibility for empowering end-to-end communication across the whole triad. In fact, they may well already be equipped with the EDI technological infrastructure necessary and the required interfaces for major retailers. Lastly, case $\mathrm{G}$ offered an example of a multi-customer warehouse, which reduces logistics costs by increasing efficiency through greater economies of scale (Kopczak et al., 2000). This solution 
usually involves multiple manufacturers, and several application examples in manifold sectors could be acknowledged. Case G presented this as a worthwhile option and a novel approach in the grocery supply chain for retailers as well, enabled by long-term partnerships with LSPs able (and willing to) sustain the required investment.

Given the research purpose, all the cases represented triadic structures (Vedel et al., 2016). In four out of the six cases (A, B, D, E), the LSP played an intermediating role, and the collaborative solution only connected the manufacturer and the retailer indirectly. Nevertheless, by applying the interpretative principles of NT, it is possible to note that the whole triad achieved benefits, and LSPs contributed not only at an operational level, but also provided benefits in terms of access to resources, network relationships, competence development, and relationship exploitation (Selviaridis and Spring, 2007; Hingley et al., 2011; Zacharia et al., 2011). Lastly, case G deserves particular attention, as the LSP operates within the triad as a coordinator and facilitator for multiple retailers with only a marginal involvement of the manufacturer (who only achieved indirect benefits, thanks to increased transport efficiency). Therefore, in this case, the nature of the LSP's role as facilitator is unique compared to the other cases, and must be appropriately acknowledged. Indeed, the LSP did not truly facilitate collaboration between manufacturers and retailers, but rather enabled a form of co-opetition among multiple retailers. Despite its limited involvement, the manufacturer has important business relationships with the other members of the triad.

\section{LSP' roles in promoting SCC}

Thanks to the adoption of NT as a theoretical lens, which led us to take logistics triads as the units of analysis (rather than either manufacturer-LSP or LSP-retailer dyads), it was possible to explore further the roles that LSPs undertake to foster SCC (Sengupta et al., 2018). Previous studies investigated the general role of LSPs (Selviaridis and Spring, 2007) or the implications of collaboration with LSPs, without explicitly dealing with their role within triads. This study confirmed that outsourcing operations to reliable LSPs helps manage supply chains as whole entities (Ellram, 1990). Nowadays, partnerships with LSPs are a key to success (Zacharia et al., 2011), as they are crucial to upholding SCC (Marchet et al., 2017).

Furthermore, building on the research findings, three possible roles for LSPs emerged. First, the LSP can create internal coalitions with one of the two members (cases F and G). In the literature, this concept generally referred to an agreement between two players to change the relationships of power and authority in triads and obtain a dominant position with respect to the excluded party (Salo et al., 2009). In this research, however, internal coalitions were meant to implement collaborative solutions aimed at increasing efficiency for the whole supply chain by improving how logistics processes were 
performed. In case G, the LSP did not create the coalition with the retailers to take advantage of manufacturers, but rather to improve the supply chain efficiency by consolidating inventories (for retailers) while simultaneously increasing transport efficiency (for manufacturers). This also supports the fact that inter-firm linkages can be actual sources of competitive advantage - through better operational efficiency, as shown in this research - and that, the larger the number of customers, the bigger the opportunities for synergies promoted by LSPs (Zacharia et al., 2011; Siltaloppi and Vargo, 2017). A second option (case C) is the tertius iungens (Obstfeld, 2005), where the LSP operates to improve its performance by facilitating the relationship between the manufacturer and the retailer.

Nevertheless, when there is no direct interaction between manufacturers and retailers regarding the considered collaborative solution, the LSP cannot play the tertius iungens role. Nor can it create an internal coalition (Salo et al., 2009), as the improved business connection is not aimed at taking advantage of the third party of the triad. Therefore, a new role was identified and named as transitum (cases A, B, D and E), which cannot be associated with any of the roles mentioned in the existing body of knowledge. This LSP can proactively improve SCC by developing new collaborative solutions that generate more value, being in the middle between the manufacturer and the retailer and having direct relationships with both. The LSP is the promoter of collaboration and the "vehicle" through which the benefits are spread along the supply chain. This is similar to what Li and Choi (2009) referred to as the bridge transfer concept, but in this case the LSP is not pursuing an opportunistic behaviour to take advantage of the other two members' disconnection (as per the tertius gaudens). Conversely, the LSP aspires to create a bridge between them to solve inefficiencies in the logistics operations. In case E, for instance, the LSP did not create a coalition with the manufacturer to take advantage of the retailer, but rather to solve existing conflicts in place between the manufacturer and the retailer related to pallet management.

\section{Discussion of the findings}

In the literature, LSPs pursue value creation through higher operational efficiencies or greater customer response (Wallenburg, 2009). The collaborative solutions emerging from this research are aligned with this perspective, mainly supporting the operational efficiency side: all the cases provided efficiency benefits (Sanchez Rodrigues et al., 2015) stemming, for example, from the optimisation of warehouse operations (case $\mathrm{G}$ ), the improvement of vehicles loading capacity utilisation (case B), the reduction of the effort to manage unloading activities (case A), the streamlining of operational and administrative processes (cases C, D and E) and inventory management and control (case F). As confirmed by the literature, the choice of opportune partners drives operational efficiency (Ellram and Cooper, 1990). However, such efficiency benefits were not always achieved in the same fashion. 
In cases A, B, and C, LSPs proposed solutions that entailed operational efficiency enabled by the large volumes handled, thus being able to offer lower rates thanks to improved scale economies. These considerations link well with the principles of NT, as illustrated by Borgatti and Halgin (2011) who suggested that any social system can be represented as a network of paths that acts as conduits for information to flow (Rowley, 1997; Brass, 2002). Consequently, this study offers a contribution to extend NT knowledge by theorizing in the middle-range through the investigated application field, confirming that the social position in a network provides access to resources but also that combinations of nodes can act as a unit, until achieving competitive advantages over other combinations of nodes.

Nevertheless, without a "collaborative culture" that involved trust, mutuality, openness and communication, as well as information exchange capabilities (Barratt, 2004), the proposed solutions would never have been implemented, as the analysis of the cases showed. LSPs enabled and reinforced this type of positive environment, making their broad logistics capabilities available for the other supply chain actors and offering a long-term experience as a warranty of the successful outcome of the initiative. For example, in Case A the retailer agreed to accept goods without performing the standard control procedures only because of the regular and trusted relationship with the LSP. Moreover, only LSPs had the potential to offer such solutions, as neither manufacturers nor retailers had the required asset availability, capabilities, or volumes. Conversely, in cases D, E, F, and $\mathrm{G}$, the initial motivation for collaboration appeared merely economic. LSPs represented trusted thirdparty players that activated the collaborative solutions in the first place by improving operational efficiency and sharing the rising benefits with the other actors. Nevertheless, they were able to promote a fair business environment, where communication and trust increased along with an improvement in the type and timeliness of shared information. At the same time, they offered access to resources and relationship exploitation as suggested by the interpretative principles of NT (Zacharia et al., 2011). In fact, they also introduced additional tools and supporting mechanisms (e.g. DesAdv in case D) and helped agree on transparent metrics to measure performance and track progress. Consequently, they triggered a virtuous cycle that relied on mutuality of benefits (Barratt and Oliveira, 2001), ultimately providing an increasing reward for positive performance on collaborative solutions. This environment characterised by mutuality and transparency required the commitment of significant resources to implement it, and organisations need to focus their attention on a small number of close relationships that can allow the greatest benefits (Soosay and Hyland, 2015). However, coherently with the middle-range approach adopted, issues of context and culture must be properly acknowledged because any theory built on a particular definition of "tie" (including 
trust) might run into problems when trying to apply it cross-culturally, and such ties can have different implications in different cultures and settings (Rowley, 1997; Borgatti and Halgin, 2011).

\section{Trust as a fundamental building block of SCC}

By critically analysing the findings of the cross-case analysis and leveraging the above considerations on the positive collaborative environment created by LSPs in triadic settings, this research unveiled trust as a fundamental building block for SCC (Barratt, 2004). This allows the focus to move away from mere economic motivations for SCC, exploring the relational mechanisms through which LSP may actually enhance trust and facilitate SCC as emerging from our case studies, and this is in line with Vlachos and Dyra (2020). Some companies might desire trust in supply chain relationships but fear that sharing knowledge or processes may result in exploitation (Hingley et al. 2011), and lack of trust hinders SCC from developing (as per case F).

As Barratt (2004) noted, trust is difficult to build, and requires strategic intent and depends on the ability of two parties to jointly recognise and invest in value co-creation opportunities (Fawcett et al., 2017). In this research, we can recognise two main facets of how LSPs acted in the logistics triads to develop collaborative solutions: trust builders or trust conductors between manufacturers and retailers.

As far as "trust-building" is concerned, LSPs genuinely support the communication and the exchange of information in an open fashion (as stated also by Hingley et al., 2011). They can actively build trust among triad actors, proactively using their position to build integrating processes via knowledge exchange and training (as shown by our Cases C, D, and E). By investing in IT systems to improve scheduling, routing and consolidation, LSPs develop visibility capability and intervene in the manufacturer-retailer complementarity, which can ultimately lead to a long-lasting triadic relationship.

As far as "trust conductor" is concerned, LSPs leverage their own current levels of interorganisational trust to connect manufacturers and retailers. This happened in Case A, in which the LSP leveraged its relationship and trust built over time with both the manufacturer and the retailer to convince the two parties to deploy the collaborative solution. In cases B and F, LSPs leveraged their trusted relationships with manufacturers to foster retailers' trust in the logistics triad, while in case G the LSP started from its relationships with the four retailers. In this sense, when actors start to collaborate, they build trust, develop triad-specific routines, and generate relational capital by triadic interactions over time, as also recalled by Yu and Huo (2018). Further, LSPs can promote unique production-distribution solutions, i.e. by knowing each supplier's production forecasts they can 
consolidate distribution to meet demand forecasting from retailers, as shown by our cases $\mathrm{B}, \mathrm{C}$, and F; this is coherent with Vlachos and Dyra (2020).

Acting either as trust builders or trust conductors, implications due to the role of LSPs in terms of relational mechanisms emerge from our analysis. Trust shared with both manufacturers and retailers enable LSPs to offer unique collaborative solutions that can be a source of differentiation from and competitive advantage over other triadic configurations (Fawcett et al., 2017). As the relationship evolves and triad parties interact and gain a deeper understanding of each other, they can also allow their partners access to resources and capabilities (cases C, D, and F). Partners may develop new routines and processes to enhance communication, and develop informal communication methods to accelerate decision-making (Vlachos and Bourlakis, 2006). Even when starting from economic motivations, trust can reinforce mutual relationships. LSPs can develop collaborative solutions that do not necessarily involve all the triad actors, but if all parties take advantage of them, they will all trust the triad more (e.g. case F) (Vlachos and Dyra, 2020).

In summary, our analysis showed that LSPs play an essential role in developing SCC solutions; they represent a real enabling factor and can actually facilitate SCC between manufacturers and retailers, who should critically choose those LSPs that are able to foster SCC and not only offer a service to monetise operational inefficiencies. In other words, in such triads, benefits will go beyond simple discounts offered to both the manufacturer and the retailer, and LSPs can build upon mutual trust and communication to become real facilitators and orchestrators in the supply chain. Consequently, SCC might be considered as a formal and differentiated program for key relationships, intended for mutual gain and defined by collaborative efforts that seek value beyond typical price negotiation and discounts, or operational efficiency, consistently with the principles of NT and the connected maximisation of a firm's ability to leverage relationships (Zacharia et al., 2011).

\section{Conclusions}

In recent decades, SCC has emerged as one of the most important research topics within the supply chain management field (Soosay and Hyland, 2015; Singh et al., 2018), having significant implications in the outsourcing of logistics activities (Zacharia et al., 2011). The present study leverages NT to explore how LSPs can foster and promote value creation through collaboration in logistics triads. It elaborates existing theory within a given empirical domain (i.e. the Italian grocery supply chain), adopting a mid-range theory approach to highlight how LSPs can facilitate SCC between manufacturers and retailers, and to support the important role of LSPs as facilitators and orchestrators in the supply chain. According to NT, outsourcing logistics operations to trusted LSPs 
can create meaningful partnerships, which ultimately produce original solutions for SCC and create a competitive advantage.

A multiple case study approach was adopted for the purpose of theory elaboration, and 7 cases were identified. They provided a comprehensive picture of the Italian grocery supply chain and collaborative solutions currently adopted, while allowing for extending and improving existing theory based on the empirical investigation. Both known solutions and original collaborative solutions were identified, driven by an increased awareness on the part of all triad members (and specifically retailers) of the impact of reorder policies on supply chain costs. All the cases showed that reducing inefficiencies leads to cost savings, which are then shared among the triad members.

The field evidence gathered and discussed also reinforces the view according to which LSPs can be essential to foster SCC, as they can exploit large volumes and asset availability to increase scale economies while improving logistics flexibility. However, this study highlighted that not only do LSPs monetise from operational inefficiencies, but also concretely help manufacturers to collaborate with retailers. They can foster SCC solutions driven not only by discounts offered to both manufacturers and retailers, but above all by mutual trust and transparency. LSPs can act as trust builders or trust conductors, developing regular and trusted relationships with the other triad members who recognise their reliability and wide logistics capabilities. Moreover, whereas collaborative solutions were usually meant to emerge from value co-creation between LSPs and their direct customers (i.e. manufacturers), it emerged that LSPs can create value, not only through collaborating with their customers but also with their customers' customers. Value creation can thus be indirect, as an actor of the triad can receive positive externalities of collaborative solutions without being directly involved.

The paper offers a contribution in terms of both academic and practical implications. From an academic perspective, it elaborates NT through a mid-range contribution on SCC in logistics triads. Building upon the idea that managing inter-organisational relationships is key to success, it explores the role of LSPs in fostering SCC going beyond the traditional dyadic LSP-customer relationship. Field-based insights highlighted different collaborative solutions in the considered empirical context, which might also create new research directions. For instance, one case represented a step forward within the theoretical stream addressing LSPs' logistics facilities design and management and specifically multi-customer warehouses. A new business paradigm was introduced, whereby the LSP is specialised according to the nature of the supply chain rather than its customers' position along the supply chain. Another contribution to extend the current theory is represented by the addition of the new transitum role played by LSPs; this integrates existing knowledge by stressing the idea that LSPs propose collaborative solutions to generate value through better operational efficiency for the whole 
triad. This is well represented by the statement according to which it is possible to see "LSPs not as box movers but as partners that can co-create solutions together" (Vlachos and Dyra, 2020; p. 297). Finally, the study supports the idea that LSPs can facilitate not only supply and demand integration, but also relational integration, hence stressing trust as a fundamental building block of SCC.

From the managerial and practical viewpoint, this study provides LSPs with useful insights to introduce and develop value creation solutions through SCC. The collaborative solutions here depicted can simultaneously sensitise SC members to the different characteristics and operability conditions, and present concrete solutions to extend their view on collaboration towards more engaging arrangements, increasing the study's practical relevance revealing new or variant routes of action (Stentoft and Rajkumar, 2018). The research can also stimulate LSPs to proactively spread collaborative practices further, while helping their customers to consider network-related benefits when choosing logistics partners and inviting the industrial community to think about trust as a powerful enabler for SCC.

Nevertheless, some limitations do exist, which in turn open up additional avenues for future research. First, the scope was restricted to the Italian grocery industry. In addition, this study only included large organisations, which might also bias obtained results. Smaller companies operating in the grocery retail supply chain might present different patterns, and further research could extend research boundaries to study triads in other countries and/or industries, or include smaller organisations. Furthermore, as trust emerged from our research as a building block of SCC, it would be interesting to deepen the study of trust mechanisms in the establishment of collaborative relationships and the proposal of SCC solutions, especially in the light of the different roles that LSPs can play in the logistics triads. In other words, since it emerged that LSPs can play different roles in the triads and be trust builders or trust conductors, it could be interesting to explore the potential connection between the role played by the LSPs and the trust mechanism involved, and investigate the underlying reasons explaining how a certain role is (potentially) connected to a certain trust mechanism and vice-versa.

Furthermore, the temporal dimension was neglected in this paper, and longitudinal studies exploring the time frame and horizon of the business relationships within logistics triads could deserve further attention. Additional research could then assess to what degree the duration of contractual relationships might be a driver of actions for LSPs. Further research might explore causal relationships between the different dimensions proposed to detect whether certain solutions for SCC might be preferable. Future studies might also formulate propositions related to potential causality and correlation between a solution and the related application context given specific contexts. Lastly, due to the increasing concerns about sustainability, both environmental and social, future inquiries 
could investigate if and how sustainability can be a driver and additional enabling factor for SCC and which role the LSP would play.

\section{References}

Andersson, D. and Norrman, A., (2002), "Procurement of logistics services - Minutes work or a multiyear project?”, European Journal of Purchasing and Supply Management, Vol. 8 No. 1, pp. 3-14.

Andersson, D., Dubois, A., Eriksson, V., Hulthén, K., and Holma, A.M. (2019), “The transport service triad: a key unit of analysis", Journal of Business and Industrial Marketing, Vol. 34 No. 1, pp. 253-266.

Attaran, M. and Attaran, S. (2007), "Collaborative supply chain management: the most promising practice for building efficient and sustainable supply chains", Business Process Management Journal, Vol. 13 No. 3, pp. 390-404.

Barratt, M. and Oliveira, A. (2001), "Exploring the experiences of collaborative planning initiatives", International Journal of Physical Distribution and Logistics Management, Vol. 31 No. 4, pp. 266-289.

Barratt, M. (2004), "Understanding the meaning of collaboration in the supply chain", Supply Chain Management: an International Journal, Vol. 9 No. 1, pp. 30-42.

Barney, J. (1991), "Firm resources and sustained competitive advantage", Journal of Management, Vol. 17 No. 1, pp. 99-120.

Bask, A.H. (2001), "Relationships among TPL providers and members of supply chains - a strategic perspective", Journal of Business and Industrial Marketing, Vol. 16 No. 6, pp. 470-486.

Beier, F. J. (1989), "Transportation contracts and the experience effect: a frame", Journal of Business Logistics, Vol. 10 No. 2, pp. 73-89.

Bottani, E. and Rizzi, A. (2006), "A fuzzy TOPSIS methodology to support outsourcing of logistics services”, Supply Chain Management: an International Journal, Vol. 11 No. 4, pp. 294-308.

Borgatti, S.P. and Halgin, D.S. (2011), “On network theory”, Organization Science, Vol. 22 No. 5, pp. 1168-1181.

Borgatti, S.P. and Li, X. (2009), "On social network analysis in a supply chain context”, Journal of Supply Chain Management, Vol. 45 No. 2, pp. 5-22.

Bourlakis, M.A. and Weightman, P.W. (2004), Food Supply Chain Management 1st ed., Blackwell Publishing, Ames, IA.

Brass, D.J. (2002). Social networks in organizations: Antecedents and consequences. Unpublished manuscript, University of Kentucky, Lexington, KY.

Caputo, M. and Mininno, V. (1996), "Internal, vertical and horizontal logistics integration in Italian grocery distribution", International Journal of Physical Distribution and Logistics Management, Vol. 26 No. 9, pp. 64-90.

Çetinkaya, S. and Lee, C.Y. (2000), "Stock replenishment and shipment scheduling for vendor-managed inventory systems", Management Science, Vol.46 No.2, pp. 217-232.

Choi, T.Y. and $\mathrm{Wu}, \mathrm{Z}$. (2009), "Triads in supply networks: theorizing buyer-supplier-supplier relationships", Journal of Supply Chain Management, Vol. 45 No.1, pp. 8-25. 
Ciborra, C.U. (1995), "EDI in the food industry - the case of Barilla in Italy", Krcmar, H., BjornAndersen, N. and O'Callaghan, R. (Eds.), EDI in Europe: How it Works in Practice, John Wiley \& Sons, New York, NY, pp. 239-58.

Claassen, M.J., Van Weele, A.J., and Van Raaij, E.M. (2008), "Performance outcomes and success factors of vendor managed inventory (VMI)", Supply Chain Management: an International Journal, Vol. 13 No.6, pp. 406-414.

Colicchia, C., Creazza, A., and Dallari, F. (2017), "Lean and green supply chain management through intermodal transport: insights from the fast moving consumer goods industry", Production Planning and Control, Vol. 28 No.4, pp. 321-334.

Daoping, W., Yao, Z., Aixia, W., and Jianhua, Y. (2011), "Analysis of Vendor Managed Inventory with the Involvement of Third-Party Logistics”, Industrial Engineering Journal, Vol. 14 No. 5, pp. 1-7.

Daugherty, P.J., Richey, R.G., Roath, A.S., Min, S., Chen, H., Arndt, A.D., and Genchev, S.E. (2006), "Is collaboration paying off for firms?", Business Horizons, Vol. 49 No. 1, pp. 61-70.

Dharanaj, C. and Parkhe, A. (2006), "Orchestrating innovation networks", Academy of Management Review, Vol. 31 No. 3, pp 659-669.

Doukidis, G., Mason, R., Lalwani, C., and Boughton, R. (2007), "Combining vertical and horizontal collaboration for transport optimisation”, Supply Chain Management: an International Journal, Vol. 12 No. 3, pp. 187-199.

Eisenhardt, K.M. (1989), "Building theories from case study research", Academy of Management Review, Vol. 14 No. 4, pp. 532-550.

Ellram, L.M. (1990), “The Supplier Selection Decision in Strategic Partnerships”, Journal of Purchasing and Materials Management, Vol. 26 No. 4, pp. 8-14.

Ellram, L.M. and Cooper, M.C. (1990), "Supply chain management, partnership and the shipper - Third party relationship", International Journal of Logistics Management, Vol. 1 No. 2, pp. 1-10.

Ellram, L.M., (1996), "The use of the case study method in logistics research", Journal of Business Logistics, Vol. 17 No. 2, pp. 93-138.

Eurostat (2020). "E-commerce statistics", available at: https://ec.europa.eu/eurostat/statisticsexplained/index.php?title=E-commerce_statistics" (accessed 03 August 2020).

Fabbe-Costes, N., Jahre, M., and Roussat, C. (2008), "Towards a Typology of the Roles of Logistics Service Providers as 'Supply Chain Integrators”, Supply Chain Forum: an International Journal, Vol. 9 No. 2, pp. 28-43.

Fabbe-Costes, N. and Roussat, C. (2011), "Supply chain integration: Views from a logistics service provider", Supply Chain Forum: an International Journal, Vol. 12 No. 2, pp 20-30.

Fawcett, A.M., Jin, Y.H., Hofer, C., Waller, M.A., and Brazhkin, V. (2016), "Sweating the assets: Asset leanness and financial performance in the motor carrier industry", Journal of Business Logistics, Vol. 37, No. 1, pp. 43-58.

Fawcett, S.E., Jin, Y.H., Fawcett, A.M., and Magnan, G. (2017), "I know it when I see it: the nature of trust, trustworthiness signals, and strategic trust construction", The International Journal of Logistics Management, Vol. 28, No. 4, pp. 914-938.

Gammelgaard, B., van Hoek, R., and Stefansson, G. (2006), "Collaborative logistics management and the role of third-party service providers", International Journal of Physical Distribution and Logistics Management, Vol. 36 No. 2, pp. 76-92. 
Gulati, R., Nohria, N., and Zaheer, A. (2000), "Strategic networks”, Strategic Management Journal, Vol. 21 No. 3, pp. 203-15.

Håkansson, H. and Snehota, I. (1995), Developing Relationships in Business Networks, International Thomson Business Press, London.

Hill, C.A. and Scudder, G.D. (2002), "The use of electronic data interchange for supply chain coordination in the food industry", Journal of Operations Management, Vol. 20 No. 4, pp. 375-387.

Hingley, M., Lindgreen, A., Grant, D., and Kane, C. (2011), "Using fourth-party logistics management to improve horizontal collaboration among grocery retailers", Supply Chain Management: an International Journal, Vol. 16 No. 5, pp. 316-327.

Holmström, J. (1998), "Business process innovation in the supply chain-a case study of implementing vendor managed inventory”. European Journal of Purchasing and Supply Management, Vol. 4 No. 2-3, pp. $127-131$.

Holmström, J., Främling, K., Kaipia, R., and Saranen, J., (2002), “Collaborative planning forecasting and replenishment: new solutions needed for mass collaboration", Supply Chain Management: an International Journal, Vol. 7 No. 3, pp. 136-145.

Huang, Y., Han, W., and Macbeth, D.K. (2020), "The complexity of collaboration in supply chain networks", Supply Chain Management: an International Journal, Vol. 25 No. 3, pp. 393-410.

Jin, J.G., Lee, D., and Cao, J.X. (2016), "Storage Yard Management in Maritime Container Terminals", Transportation Science, Vol. 50 No. 4, pp. 1300-1313.

Ketokivi, M. and Choi, T.Y. (2014), "Renaissance of case research as a scientific method", Journals of Operations Management, Vol. 34 No. 1, pp 232-240.

Kopczak, L.R., Lee, H., and Whang, S. (2000), Note on logistics in the information age, Graduate School of Business Stanford University: Stanford, CA.

Lai, F., Li, D., Wang, Q., and Zhao, X. (2008), "The information technology capability of third-party logistics providers: a resource-based view and empirical evidence from China", Journal of Supply Chain Management, Vol. 44 No. 3, pp. 22-38.

Larson, P.D. and Gammelgaard, B. (2001), "The logistics triad: survey and case study results", Transportation Journal, Vol. 41 No. 2, pp. 71-82.

Leonard, L.N.K. and Clemons Davis, C. (2006), "Supply chain replenishment: before-and-after EDI implementation", Supply Chain Management: an International Journal, Vol. 11 No. 3, pp. 225-232.

Li, M. and Choi, T.Y. (2009), "Triads in Services Outsourcing: Bridge, Bridge Decay and Bridge Transfer", Journal of Supply Chain Management, Vol. 45 No. 3, pp. 27-39.

Marchet, G., Melacini, M., Perotti, S., Sassi, C., and Tappia, E. (2017), "Value creation models in the 3PL industry: what 3PL providers do to cope with shipper requirements", International Journal of Physical Distribution and Logistics Management, Vol. 47 No. 6, pp. 472-494.

Miles, M.B. and Huberman, A.M. (1994), Qualitative Data Analysis: An Expanded Sourcebook, 2nd ed., Sage Publications, Thousand Oaks, CA.

Nätti, S., Pekkarinen, S., Hartikka, A., and Holappa, T. (2014), "The intermediator role in value co-creation within a triadic business service relationship", Industrial Marketing Management, Vol. 43 No. 6, pp. 977-984. 
Nielsen, (2019), "Nielsen Growth Reporter Europe, Q2 2019", available at: https://www.nielsen.com/eu/en/insights/article/2019/fmcg-growth-in-europe-bounces-back-in-the-secondquarter-of-2019/ (accessed 27 October 2019).

Obstfeld, D. (2005), "Social networks, the tertius iungens orientation, and involvement in innovation", Administrative Science Quarterly, Vol. 50 No. 1, pp. 100-130.

OECD, (2005), The Measurement of Scientific and Technological Activities, Oslo Manual: Guidelines for Collecting and Interpreting Innovation Data, third ed. Paris, Organisation for Economic Co-operation and Development (OECD).

Olorunniwo, F.O. and $\mathrm{Li}, \mathrm{X}$. (2010), "Information sharing and collaboration practices in reverse logistics", Supply Chain Management: an International Journal, Vol. 15 No. 6, pp. 454-462.

Pramatari, K. (2007), "Collaborative supply chain practices and evolving technological approaches", Supply Chain Management: an International Journal, Vol. 12 No. 3, pp. 210-220.

Ralston, P.M., Richey, R.G. and Grawe, S.J (2017), “The past and future of supply chain collaboration: a literature synthesis and call for research", The International Journal of Logistics Management, Vol. 28 No. 2, pp. 508-530.

Razzaque, M.A. and Sheng, C.C. (1998), "Outsourcing of logistics functions: a literature survey", International Journal of Physical Distribution and Logistics Management, Vol. 28 No. 2, pp. 89-107.

Rowley, T.J. (1997), "Moving beyond dyadic ties: A network theory of stakeholder influences", Academy of Management Review, Vol. 22 No. 4, pp. 887-910.

Salo, A., Tähtinen, J., and Ulkuniemi, P. (2009), "Twists and turns of triadic business relationship recovery", Industrial Marketing Management, Vol. 38 No. 6, pp. 618-632.

Sanchez Rodrigues, V., Harris, I., and Mason, R. (2015), "Horizontal logistics collaboration for enhanced supply chain performance: an international retail perspective", Supply Chain Management: an International Journal, Vol. 20 No. 6, pp. 631-647.

Saunders, M., Lewis, P., and Thornhill, A. (2009), Research Methods for Business Students 5th ed., Prentice Hall, London.

Selviaridis, K. and Spring, M. (2007), "Third party logistics: a literature review and research agenda", International Journal of Logistics Management, Vol. 18 No. 1, pp. 125-150.

Selviaridis, K. and Norrman, A. (2015), "Performance-based contracting for advanced logistics services: Challenges in its adoption, design and management". International Journal of Physical Distribution and Logistics Management, Vol. 45 No. 6, pp. 592-617.

Sengupta, S., Niranjan, T.T., and Krishnamoorthy, M. (2018), "Trends and directions in service triads research", International Journal of Physical Distribution and Logistics Management, Vol. 48 No. 3, pp. 333-360.

Siltaloppi, J. and Vargo, S.L. (2017), "Triads: A review and analytical framework", Marketing Theory, Vol. 17 No. 4, pp. 395-414

Simatupang, T.M. and Sridharan, R. (2005), "An integrative framework for supply chain collaboration", International Journal of Logistics Management, Vol. 16 No. 2, pp. 257-274.

Simmel, G. (1950), “The Triad”, in Wolff, K.H. (Ed.), The Sociology of George Simmel, Free Press, Glencoe, IL, pp. 145-169 
Singh, H., Garg, R., and Sachdeva, A. (2018), "Supply chain collaboration: A state-of-the-art literature review”, Uncertain Supply Chain Management, Vol. 6 No. 2, pp. 149-180.

Singh, P.J. and Power, D. (2009), "The nature and effectiveness of collaboration between IRMS, their customers and suppliers: a supply chain perspective", Supply Chain Management: an International Journal, Vol. 14 No. 3, pp. 189-200.

Soosay, C.A., Hyland, P.W., and Ferrer, M. (2008), "Supply chain collaboration: capabilities for continuous innovation", Supply Chain Management: an International Journal, Vol. 13 No. 2, pp. 160-169.

Soosay, C.A. and Hyland, P.W. (2015), "A decade of supply chain collaboration and directions for future research.”, Supply Chain Management: an International Journal, Vol. 20 No. 6, pp. 613-630.

Stank, T.P., Pellathy, D.A., In, J., Mollenkopf, D.A., and Bell, J.E. (2017), "New Frontiers in Logistics Research: Theorizing at the Middle Range", Journal of Business Logistics, Vol. 38 No. 1, pp. 6-17.

Stentoft, J. and Rajkumar, C. (2018), "Balancing theoretical and practical relevance in supply chain management research", International Journal of Physical Distribution and Logistics Management, Vol. 48 No. 5, pp. 504-523.

Vedel, M., Holma, A.M., and Havila, V. (2016), “Conceptualizing inter-organizational triads", Industrial Marketing Management, Vol. 57 No. 1, pp. 139-47.

Vlachos, I. and Bourlakis, M. (2006), "Supply Chain Collaboration Between Retailers and Manufacturers: Do They Trust Each Other?”, Supply Chain Forum: an International Journal, Vol. 7 No. 1, pp. 70-80.

Vlachos, I. and Dyra, S. (2020), "Theorizing coordination, collaboration and integration in multi-sourcing triads (B3B triads)", Supply Chain Management: an International Journal, Vol. 25 No. 3, pp. 285-300.

Voss, C., Tsikriktsis, N., and Frohlich, M. (2002), "Case research in operations management", International Journal of Operations and Production Management, Vol. 22 No. 2, pp. 195-219.

Wallenburg, C.M. (2009), "Innovation in logistics outsourcing relationships: proactive improvement by logistics service providers as a driver of customer loyalty", Journal of Supply Chain Management, Vol. 45 No. 2, pp. 75-93.

Waller, M., Johnson, M.E., and Davis, T. (1999), "Vendor-managed inventory in the retail supply chain", Journal of Business Logistics, Vol. 20 No. 1, pp. 183-204.

Wilding, R. and Juriado, R. (2004), "Customer perceptions on logistics outsourcing in the European consumer goods industry", International Journal of Physical Distribution and Logistics Management, Vol. 34 No. 8, pp. 628-644.

Yang, Y. and Liu, Z.X. (2007), "A system dynamic model of vendor managed inventory and third party logistics”, Systems Engineering, Vol. 25 No. 7, pp. 38-44

Yao, Y. and Dresner, M. (2008), "The inventory value of information sharing, continuous replenishment, and vendor-managed inventory", Transportation Research Part E: Logistics and Transport Review, Vol. 44 No. 3, pp. 361-378.

Yin, R.K. (2009), Case Study Research, 4th ed., Sage Publications, Thousand Oaks, CA.

Yu, Y. and Huo, B. (2018), "Supply chain quality integration: relational antecedents and operational consequences", Supply Chain Management: an International Journal, Vol. 23 No. 3, pp. 188-206.

Zacharia, Z.G., Sanders, N.R., and Nix, N.W. (2011) "The emerging role of the third-party logistics provider (3PL) as an orchestrator", Journal of Business Logistics, Vol. 32 No. 1, pp. 40-54. 
Zhen, L., Jiang, X., Lee, L.H., and Chew, E.P. (2013). "A Review on Yard Management in Container Terminals". Industrial Engineering and Management Systems, Vol.12 No.4, pp. 289-304. 


\begin{tabular}{|c|c|c|c|}
\hline \multirow[t]{2}{*}{ Case } & \multicolumn{3}{|c|}{$\begin{array}{l}\text { Triads components (for each case, with related } 2018 \text { revenues and roles of the involved } \\
\text { informants) }\end{array}$} \\
\hline & M & LSP & $\mathbf{R}$ \\
\hline A & $\begin{array}{c}\mathrm{M}_{\mathrm{A}} \\
(€ 2,508 \mathrm{M}) \\
\text { Logistics manager; } \\
\text { Customer service manager }\end{array}$ & $\begin{array}{c}\mathrm{LSP}_{\mathrm{A}} \\
(€ 111 \mathrm{M}) \\
\text { Logistics director; Sales } \\
\text { director; } \\
\text { Plant manager }\end{array}$ & $\begin{array}{c}\mathrm{R}_{\mathrm{A}} \\
(€ 7,746 \mathrm{M}) \\
\text { Logistics manager; } \\
\text { Plant manager }\end{array}$ \\
\hline B & $\begin{array}{c}\mathrm{M}_{\mathrm{B}} \\
(€ 1,312 \mathrm{M}) \\
\text { SC manager; } \\
\text { Customer service manager } \\
\end{array}$ & $\begin{array}{c}\mathrm{LSP}_{\mathrm{B}} \\
(€ 108 \mathrm{M}) \\
\text { Managing director; } \\
\text { Business development manager }\end{array}$ & $\begin{array}{c}\mathrm{R}_{\mathrm{B}} \\
(€ 5,265 \mathrm{M}) \\
\text { Logistics manager; } \\
\text { SC director } \\
\end{array}$ \\
\hline $\mathrm{C}$ & $\begin{array}{c}\mathrm{M}_{\mathrm{C}} \\
(€ 1,301 \mathrm{M}) \\
\text { Logistics manager; } \\
\text { SC development manager }\end{array}$ & $\begin{array}{c}\mathrm{LSP}_{\mathrm{C}} \\
(€ 262 \mathrm{M}) \\
\text { Managing director; Marketing } \\
\text { manager }\end{array}$ & $\begin{array}{c}\mathrm{R}_{\mathrm{C}} \\
(€ 2,542 \mathrm{M}) \\
\text { SC manager; } \\
\text { Senior buyer }\end{array}$ \\
\hline D & $\begin{array}{c}\mathrm{M}_{\mathrm{D} 1} \\
(€ 103 \mathrm{M}) \\
\text { SC manager; } \\
\text { Customer service manager } \\
\mathrm{M}_{\mathrm{D} 2} \\
(€ 201 \mathrm{M}) \\
\text { Logistics manager } \\
\end{array}$ & $\begin{array}{c}\mathrm{LSP}_{\mathrm{D}} \\
(€ 283 \mathrm{M}) \\
\text { CEO; } \\
\text { Business development manager }\end{array}$ & $\begin{array}{c}\mathrm{R}_{\mathrm{D}} \\
(€ 2,113 \mathrm{M}) \\
\text { Logistics manager; } \\
\text { Purchasing manager }\end{array}$ \\
\hline $\mathrm{E}$ & $\begin{array}{c}\mathrm{M}_{\mathrm{E}} \\
(€ 247 \mathrm{M}) \\
\text { Logistics manager; } \\
\text { Customer service manager }\end{array}$ & $\begin{array}{c}\mathrm{LSP}_{\mathrm{E}} \\
(€ 811 \mathrm{M}) \\
\text { Logistics division director; } \\
\text { Business development manager }\end{array}$ & $\begin{array}{c}\mathrm{R}_{\mathrm{E}} \\
(€ 1,332 \mathrm{M}) \\
\text { SC manager; } \\
\text { Buyer coordinator } \\
\end{array}$ \\
\hline $\mathrm{F}$ & $\begin{array}{c}\mathrm{M}_{\mathrm{F}} \\
(€ 256 \mathrm{M}) \\
\text { Logistics manager; } \\
\text { Customer service director } \\
\end{array}$ & $\begin{array}{c}\mathrm{LSP}_{\mathrm{F}} \\
(€ 420 \mathrm{M}) \\
\text { CEO; } \\
\text { Head of marketing } \\
\end{array}$ & $\begin{array}{c}\mathrm{R}_{\mathrm{F}} \\
(€ 1,003 \mathrm{M}) \\
\text { Logistics manager; } \\
\text { SC manager }\end{array}$ \\
\hline \multirow{4}{*}{ G } & \multirow{4}{*}{$\begin{array}{c}\mathrm{M}_{\mathrm{G}} \\
(€ 2,588 \mathrm{M}) \\
\text { Logistics manager; } \\
\text { SC development manager }\end{array}$} & \multirow{4}{*}{$\begin{array}{c}\mathrm{LSP}_{\mathrm{G}} \\
(€ 258 \mathrm{M}) \\
\text { Logistics director; Sales } \\
\text { director; } \\
\text { Plant manager }\end{array}$} & $\begin{array}{c}\mathrm{R}_{\mathrm{G} 1} \\
(€ 670 \mathrm{M}) \\
\text { Logistics director; } \\
\text { SC manager } \\
\end{array}$ \\
\hline & & & $\begin{array}{c}\mathrm{R}_{\mathrm{G} 2} \\
(€ 998 \mathrm{M}) \\
\text { Logistics director; Purchasing } \\
\text { manager } \\
\end{array}$ \\
\hline & & & $\begin{array}{c}\mathrm{R}_{\mathrm{G} 3} \\
(€ 545 \mathrm{M}) \\
\text { Logistics manager; } \\
\text { Procurement executive assistant }\end{array}$ \\
\hline & & & $\begin{array}{c}\mathrm{R}_{\mathrm{G} 4} \\
(€ 780 \mathrm{M}) \\
\text { Logistics manager; } \\
\text { Customer service manager; } \\
\text { Purchasing manager }\end{array}$ \\
\hline
\end{tabular}

Table 1 - Case descriptions (Key: $M=$ Manufacturer; $L S P=$ Logistics service provider; $R=$ retailer . 2018 revenues for each company are included in brackets; the roles of the informants for each company are reported in italics). 


\begin{tabular}{|c|c|}
\hline $\begin{array}{l}\text { Quality } \\
\text { criteria }\end{array}$ & Actions taken \\
\hline \multirow{4}{*}{$\begin{array}{l}\text { Internal } \\
\text { validity }\end{array}$} & Research design based on well-established theories from the literature \\
\hline & Data collected through interviews were analysed according to categories from the literature \\
\hline & Data display in tabular data forms to facilitate cross-case analysis and pattern matching \\
\hline & Multiple informants provided similar answers about the same phenomenon \\
\hline \multirow{6}{*}{$\begin{array}{l}\text { Construct } \\
\text { validity }\end{array}$} & $\begin{array}{l}\text { Data triangulation employing multiple sources of evidence (interviews, internal presentations, } \\
\text { industry reports, websites) to triangulate informants' responses }\end{array}$ \\
\hline & Engagement of peer researchers to review interview protocol \\
\hline & $\begin{array}{l}\text { Explanation of the academic terminology used to informants before each interview to avoid } \\
\text { misunderstandings }\end{array}$ \\
\hline & $\begin{array}{l}\text { Nested approach within the considered unit of analysis and involvement of multiple informants } \\
\text { (representing different internal functions and different actors in the supply chain) to compare } \\
\text { and contrast responses }\end{array}$ \\
\hline & $\begin{array}{l}\text { Share of preliminary results and conclusions drafts with key informants to compare and contrast } \\
\text { views }\end{array}$ \\
\hline & $\begin{array}{l}\text { Presentation of results to peer researchers familiar with the studied phenomenon, to obtain } \\
\text { feedback about case analysis and check for validity }\end{array}$ \\
\hline \multirow{4}{*}{$\begin{array}{l}\text { External } \\
\text { validity }\end{array}$} & Cross-case analysis \\
\hline & Systematic data collection \\
\hline & $\begin{array}{l}\text { Collecting data and providing case descriptions to help highlight elements in common with other } \\
\text { contexts }\end{array}$ \\
\hline & Describing the logic and criteria applied for case selection to allow for analytical generalisation \\
\hline \multirow{3}{*}{ Reliability } & $\begin{array}{l}\text { Developing and continuously updating a case study database (including interview transcriptions, } \\
\text { codes and memos), to ensure complete documentation of the data analysis procedure }\end{array}$ \\
\hline & Developing and using an interview protocol for data collection across the cases \\
\hline & Explanation of data analysis procedures \\
\hline
\end{tabular}

Table 2 - Research quality and validity dimensions 


\begin{tabular}{|c|c|c|c|c|c|}
\hline Case & Solution & Description & LSP role & LSP action & Novelty elements \\
\hline A & $\begin{array}{l}\text { Drop-and- } \\
\text { hook }\end{array}$ & $\begin{array}{l}\text { Speeding-up unloading } \\
\text { operations at retailers' } \\
\text { DC. The LSP leaves a full } \\
\text { semi-trailer at the } \\
\text { warehouse's docks and } \\
\text { takes off with an empty } \\
\text { semi-trailer. The retailer } \\
\text { unloads the semi-trailer } \\
\text { later, according to its } \\
\text { planning. }\end{array}$ & $\begin{array}{l}\text { LSP is proactive to discuss with } \\
\text { the retailer to improve operations } \\
\text { for the whole chain, without } \\
\text { taking advantage of one of the } \\
\text { two other members of the triad } \\
\text { and benefitting from the mutual } \\
\text { trust and transparency with both. }\end{array}$ & $\begin{array}{l}\text { The LSP offers a new } \\
\text { way to carry out logistics } \\
\text { operations, improving } \\
\text { existing processes that it } \\
\text { currently manages }\end{array}$ & $\begin{array}{l}\text { The solution can help reduce } \\
\text { operational time and increase assets' } \\
\text { usage. So far, it has mainly been } \\
\text { proposed in maritime logistics to } \\
\text { manage container at ports and inland } \\
\text { terminals. In this case, the solution is } \\
\text { applied within the grocery supply chain } \\
\text { to optimise inbound operations at DC } \\
\text { and achieve benefits for the whole } \\
\text { chain thanks to the proactive role of the } \\
\text { LSP. }\end{array}$ \\
\hline B & $\begin{array}{l}\text { Order } \\
\text { pooling }\end{array}$ & $\begin{array}{l}\text { The LSP asks the retailer } \\
\text { for synchronising the } \\
\text { deliveries of products } \\
\text { shipped from the same } \\
\text { manufacturer's warehouse } \\
\text { to improve vehicles' } \\
\text { saturation and routing }\end{array}$ & $\begin{array}{l}\text { The LSP is proactive in offering } \\
\text { the retailer a solution that takes } \\
\text { benefits to the manufacturer as } \\
\text { well and is enabled by the trust } \\
\text { in place between the LSP and the } \\
\text { two other actors. }\end{array}$ & $\begin{array}{l}\text { The LSP detects } \\
\text { opportunities for volume } \\
\text { consolidation and } \\
\text { improved efficiency, thus } \\
\text { offers a solution to } \\
\text { streamline existing } \\
\text { processes }\end{array}$ & $\begin{array}{l}\text { First investigation of a new } \\
\text { collaborative solution, which allows for } \\
\text { a more intensive use of transport assets } \\
\text { (e.g. combining high volume, less } \\
\text { dense shipments with denser, lower } \\
\text { volume goods). }\end{array}$ \\
\hline $\mathrm{C}$ & $\begin{array}{l}\text { Inventories } \\
\text { co-location }\end{array}$ & $\begin{array}{l}\text { The LSP holds inventories } \\
\text { of a manufacturer and a } \\
\text { retailer within the same } \\
\text { warehouse }\end{array}$ & $\begin{array}{l}\text { The LSP acts as a facilitator for } \\
\text { the overall supply chain } \\
\text { optimisation, and all the triad's } \\
\text { members are involved. Thanks to } \\
\text { its mediation, manufacturer and } \\
\text { retailer can leverage on a } \\
\text { collaborative solution otherwise } \\
\text { inapplicable. It is also the } \\
\text { guarantor of the initiative, being } \\
\text { a neutral arbitrator thanks to its } \\
\text { impartial position. }\end{array}$ & $\begin{array}{l}\text { The LSP develops a } \\
\text { specific logistics facility, } \\
\text { which requires high } \\
\text { commitment and specific } \\
\text { investments. }\end{array}$ & $\begin{array}{l}\text { A step forward in logistics facilities } \\
\text { grouping different players' inventories. } \\
\text { A new business paradigm can be } \\
\text { formalised, where the LSP is } \\
\text { specialised according to the nature of } \\
\text { the supply chain rather than the } \\
\text { position in the chain. }\end{array}$ \\
\hline $\mathrm{D}$ & $\begin{array}{l}\text { LSP's } \\
\text { DesAdv }\end{array}$ & $\begin{array}{l}\text { The LSP takes } \\
\text { responsibility for } \\
\text { dispatching DesAdv to the } \\
\text { retailer on behalf of the } \\
\text { manufacturer, using an } \\
\text { existing platform to } \\
\text { interface with multiple } \\
\text { retailers. }\end{array}$ & $\begin{array}{l}\text { The LSP offers to connect the } \\
\text { manufacturer and the retailer, } \\
\text { managing the information on } \\
\text { behalf of the manufacturer. }\end{array}$ & $\begin{array}{l}\text { The LSP improves } \\
\text { information sharing and } \\
\text { the efficiency of } \\
\text { unloading activities } \\
\text { through the optimisation } \\
\text { of administrative tasks. }\end{array}$ & $\begin{array}{l}\text { EDI benefits are supported in terms of } \\
\text { higher coordination among players. IT } \\
\text { is also supported as a relevant factor to } \\
\text { improve supply chain activities. } \\
\text { In addition, the case shed light on a } \\
\text { new EDI-based collaborative solution. }\end{array}$ \\
\hline $\mathrm{E}$ & $\begin{array}{l}\text { Pallet } \\
\text { pooling }\end{array}$ & $\begin{array}{l}\text { The LSP takes control } \\
\text { over pallet management, }\end{array}$ & $\begin{array}{l}\text { The LSP proactively becomes } \\
\text { the supply chain's key interface, } \\
\text { disintermediating the }\end{array}$ & $\begin{array}{l}\text { The LSP streamlines } \\
\text { pallet management, }\end{array}$ & $\begin{array}{l}\text { Pallet pooling is proposed as a solution } \\
\text { to reduce pallet management } \\
\text { complexity and streamline the }\end{array}$ \\
\hline
\end{tabular}




\begin{tabular}{|l|l|l|l|l|l|}
\hline & & $\begin{array}{l}\text { offering its customers a } \\
\text { rental service. }\end{array}$ & $\begin{array}{l}\text { manufacturer and the retailer } \\
\text { about pallet management. }\end{array}$ & $\begin{array}{l}\text { reducing contractual } \\
\text { disputes as well. }\end{array}$ & $\begin{array}{l}\text { recollection process. Moreover, a pallet } \\
\text { pooling solution is explored within } \\
\text { logistics triads and with the direct } \\
\text { involvement of the LSP. }\end{array}$ \\
\hline F & LSP's VMI & $\begin{array}{l}\text { Unlike traditional VMI, } \\
\text { the LSP acts on behalf of } \\
\text { the manufacturer to } \\
\text { manage the replenishment } \\
\text { process of the retailer. }\end{array}$ & $\begin{array}{l}\text { The LSP works with the } \\
\text { manufacturer to improve its } \\
\text { operational efficiency, enabling } \\
\text { the manufacturer to improve its } \\
\text { collaborative relationship with } \\
\text { the retailer. The LSP also openly } \\
\text { shares information with the two } \\
\text { of them, increasing transparency } \\
\text { and improving the mutual } \\
\text { exchange of information. }\end{array}$ & $\begin{array}{l}\text { The LSP proactively asks } \\
\text { the manufacturer to } \\
\text { manage its VMI } \\
\text { agreement with the } \\
\text { retailer, increasing } \\
\text { supply chain efficiency. } \\
\text { streamline supply chain processes. In } \\
\text { this solution, LSP is an intermediary } \\
\text { who can improve VMI thanks to } \\
\text { savings due to higher vehicles' } \\
\text { saturation and usage. }\end{array}$ \\
\hline G & $\begin{array}{l}\text { Multi- } \\
\text { retailer } \\
\text { warehouse }\end{array}$ & $\begin{array}{l}\text { The LSP created a } \\
\text { logistics hub for jointly } \\
\text { managing inventories of } \\
\text { different retailers }\end{array}$ & $\begin{array}{l}\text { The LSP plays a crucial enabling } \\
\text { role for the solution, creating a } \\
\text { strong long-term partnership } \\
\text { with retailers while bringing } \\
\text { indirect benefits to } \\
\text { manufacturers. }\end{array}$ & $\begin{array}{l}\text { Following retailers' } \\
\text { requirements and } \\
\text { constraints, the LSP } \\
\text { created a devoted multi- } \\
\text { customer logistics } \\
\text { facility. }\end{array}$ & $\begin{array}{l}\text { Multi-customer warehousing allows a } \\
\text { reduction in logistics costs by } \\
\text { increasing efficiency through higher } \\
\text { scale economies. In this case, multi- } \\
\text { customer warehousing emerges as a } \\
\text { feasible solution for collaboration } \\
\text { among retailers and not only } \\
\text { manufacturers. }\end{array}$ \\
& & &
\end{tabular}

Table 3 - Summary of case findings concerning solutions' operationalisation 


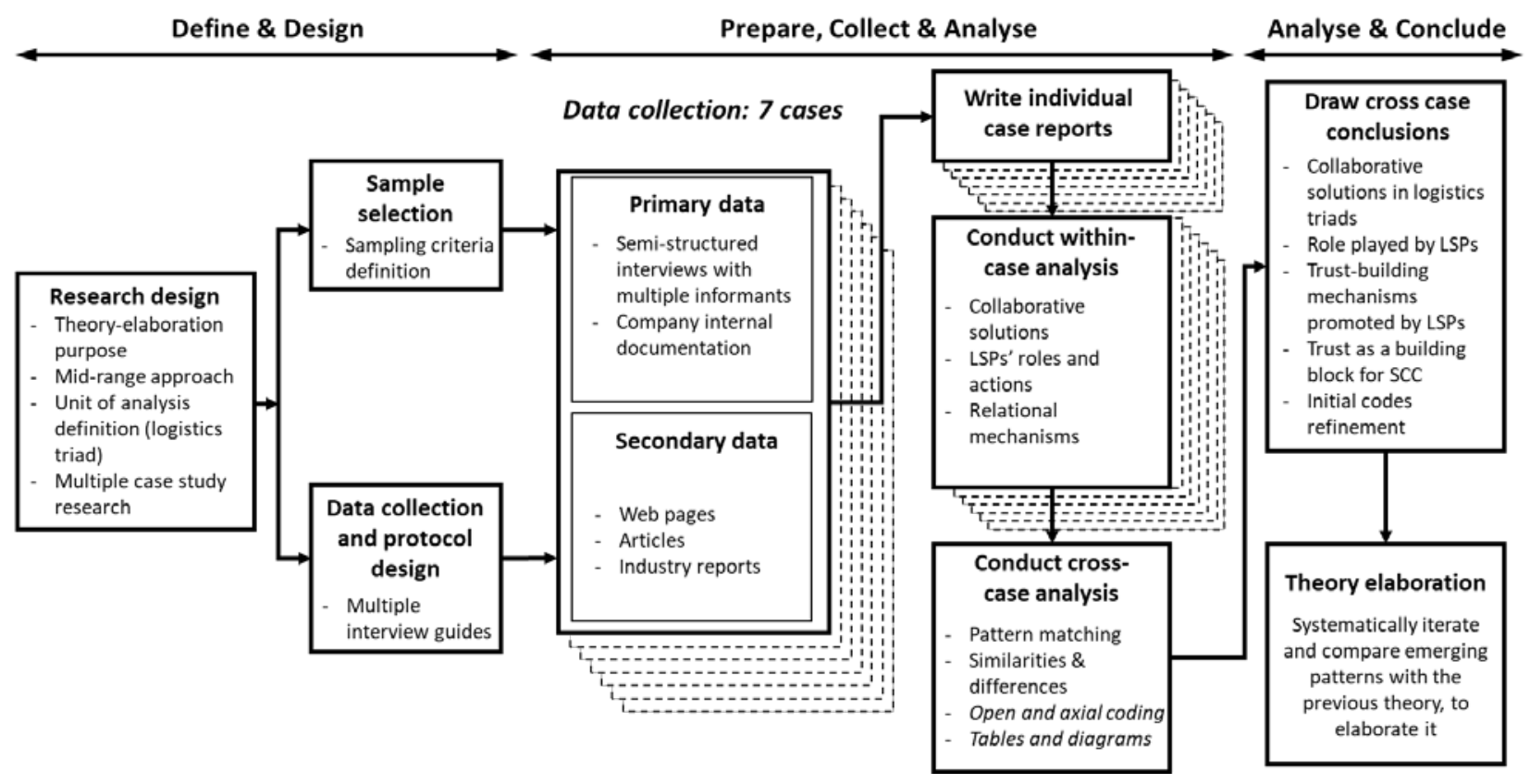

Figure 1 - Research process 


\section{Appendix}

\section{INTERVIEW GUIDE - MANUFACTURERS}

\section{SECTION 1. COMPANY INFORMATION}

1.1. What are your company's 2018 revenues?

1.2. What type of products does your company manufacture?

1.3. Can you describe how your supply chain/production and logistics network is arranged?

1.4. Can you identify relevant examples of triads involving your company? More in detail, triads are interorganisational structures that require the association of three actors and the connectedness of relations among them. In this research, the focus is upon logistics triads, defined as "cooperative, three-way relationships between a buyer of goods, the supplier of those goods and an LSP moving and/or storing the goods between buyer and supplier".

SECTION 2. THE TRIAD (for each relevant example of triad that emerged from question 1.4)

2.1. Can you tell us who the members of the triad are (companies' names, and contact points within these companies)?

2.2. Can you describe the type of relationships in place with the other members of the triad?

2.3. Can you describe how the typical "order-to-delivery" process works in the considered triad?

2.4. Can you describe how the triad generally works, in terms of activities and processes?

2.5. Can you describe your role in the triad and generally what you do, in terms of activities and processes?

2.6. What activities, processes and decisions are outsourced to your logistics service provider?

2.7. Can you identify any collaborative solution in place in the considered triad?

SECTION 3. THE SUPPLY CHAIN COLLABORATION SOLUTION (for each collaborative solution that emerged from question 2.5)

3.1. Can you describe the collaborative solution within the triad, and how it works?

3.2. Can you tell us your reasons behind the design and implementation of this solution?

3.3. Can you tell us who made the first move originally? Your company? The logistics service provider? The retailer?

3.4. Can you describe your role in this solution?

3.5. Can you tell us what capabilities and investments have been necessary to put this solution in place?

3.6. Can you describe what actions were taken to implement the solution?

3.7. Can you describe what are, in your opinion, the main benefits arising (not only in terms of efficiency)? Did any additional cost arise?

3.8. In a nutshell, can you tell us what factors made this solution a successful one?

3.9. Did you find similar solutions before, or are you aware of similar solutions in place in other triads (thus involving other companies)? 


\section{INTERVIEW GUIDE - RETAILERS}

\section{SECTION 1. COMPANY INFORMATION}

1.1. What are your company's 2018 revenues?

1.2. What type of products does your company sell through the grocery retail channel?

1.3. Can you describe how your supply chain/production and logistics network is arranged?

1.4. Can you identify relevant examples of triads involving your company? More in detail, triads are interorganisational structures that require the association of three actors and the connectedness of relations among them. In this research, the focus is upon logistics triads, defined as "cooperative, three-way relationships between a buyer of goods, the supplier of those goods and an LSP moving and/or storing the goods between buyer and supplier".

SECTION 2. THE TRIAD (for each relevant example of triad that emerged from question 1.4)

2.1. Can you tell us who the members of the triad are (companies' names, and contact points within these companies)?

2.2. Can you describe the type of relationships in place with the other members of the triad?

2.3. Can you describe how the typical "order-to-delivery" process works in the considered triad?

2.4. Can you describe how the triad generally works, in terms of activities and processes?

2.5. Can you describe your role in the triad and generally what you do, in terms of activities and processes?

2.6. What activities, processes and decisions are outsourced to your logistics service provider?

2.7. Can you identify any collaborative solution in place in the considered triad?

SECTION 3. THE SUPPLY CHAIN COLLABORATION SOLUTION (for each collaborative solution that emerged from question 2.5)

3.1. Can you describe the collaborative solution within the triad, and how it works?

3.2. Can you tell us your reasons behind the design and implementation of this solution?

3.3. Can you tell us who made the first move originally? Your company? The manufacturer? The logistics service provider?

3.4. Can you describe your role in this solution?

3.5. Can you tell us what capabilities and investments have been necessary to put this solution in place?

3.6. Can you describe what actions were taken to implement the solution?

3.7. Can you describe what are, in your opinion, the main benefits arising (not only in terms of efficiency)? Did any additional cost arise?

3.8. In a nutshell, can you tell us what factors made this solution a successful one?

3.9. Did you find similar solutions before, or are you aware of similar solutions in place in other triads (thus involving other companies)? 


\section{INTERVIEW GUIDE - LOGISTICS SERVICE PROVIDERS \\ SECTION 1. COMPANY INFORMATION}

1.1. What are your company's 2018 revenues?

1.2. What industries are considered within your business scope? What type of products does your company distribute?

1.3. Can you describe how your supply chain/logistics network is arranged?

1.4. Can you identify relevant examples of triads involving your company? More in detail, triads are interorganisational structures that require the association of three actors and the connectedness of relations among them. In this research, the focus is upon logistics triads, defined as "cooperative, three-way relationships between a buyer of goods, the supplier of those goods and an LSP moving and/or storing the goods between buyer and supplier".

SECTION 2. THE TRIAD (for each relevant example of triad that emerged from question 1.4)

2.1. Can you tell us who the members of the triad are (companies' names, and contact points within these companies)?

2.2. Can you describe the type of relationships in place with the other members of the triad?

2.3. Can you describe how the typical "order-to-delivery" process works in the considered triad?

2.4. Can you describe how the triad generally works, in terms of activities and processes?

2.5. Can you describe your role in the triad and generally what you do, in terms of activities and processes?

2.6. Can you identify any collaborative solution in place in the considered triad?

SECTION 3. THE SUPPLY CHAIN COLLABORATION SOLUTION (for each collaborative solution that emerged from question 2.5)

3.1. Can you describe the collaborative solution within the triad, and how it works?

3.2. Can you tell us your reasons behind the design and implementation of this solution?

3.3. Can you tell us who made the first move originally? Your company? The manufacturer? The retailer?

3.4. Can you describe your role in this solution?

3.5. Can you tell us what capabilities and investments have been necessary to put this solution in place?

3.6. Can you describe what actions were taken to implement the solution?

3.7. Can you describe what are, in your opinion, the main benefits arising (not only in terms of efficiency)? Did any additional cost arise?

3.8. In a nutshell, can you tell us what factors made this solution a successful one?

3.9. Did you find similar solutions before, or are you aware of similar solutions in place in other triads (thus involving other companies)? 